\title{
Modelling the Role of Pellet Crack Motion in the $(r-\theta)$ Plane Upon Pellet-Clad Interaction in Advanced Gas Reactor Fuel
}

\author{
T.A. Haynes ${ }^{1}$, J.A. Ball ${ }^{2} \&$ M.R. Wenman ${ }^{1} *$ \\ ${ }^{1}$ Centre for Nuclear Engineering \& Department of Materials, Imperial College London, Exhibition Rd., London, SW7 2AZ \\ ${ }^{2}$ EDF Energy, Barnett Way, Gloucester, GL4 3RS \\ * Corresponding Author
}

\begin{abstract}
A finite element model of pellet fragment relocation in the $r-\theta$ plane of advanced gas-cooled reactor (AGR) fuel is presented under conditions of both 'hard' and 'soft' pellet-clad interaction. The model was able to predict the additional radial displacement of fuel fragments towards the cladding as well as the stress concentration on the inner surface resulting from the azimuthal motion of pellet fragments. The model was subjected to a severe ramp in power from both full power and after a period of reduced power operation; in the former, the maximum hoop stress in the cladding was found to be increased by a factor of 1.6 as a result of modelling the pellet fragment motion. The pellet-clad interaction was found to be relatively insensitive to the number of radial pellet crack. However, it was very sensitive to both the coefficient of friction used between the clad and pellet fragments and power ramp duration.
\end{abstract}

\section{Highlights}

- Finite element modelling of pellet relocation in the $(r-\theta)$ plane of nuclear fuel.

- 'Soft' and 'hard' PCI have been predicted in a cracked nuclear fuel pellet.

- Stress concentration in the cladding ahead of radial pellet cracks is predicted.

- The model is very sensitive to the coefficient of friction and power ramp duration.

- The model is less sensitive to the number of cracks assumed.

\section{Key Words}

PCI, Nuclear Fuel, Relocation, AGR

\section{Introduction}

There are currently fourteen advanced gas-cooled reactors (AGRs) in operation at seven locations in England and Scotland. Operation is now projected to continue into the 2030s. The reactors can be characterised by a graphite moderator, carbon dioxide primary circuit at 4.1 $\mathrm{MPa}$ and the use of stainless steel cladding surrounding annular fuel pellets. Operations involve a much greater range of conditions than light water reactors (LWRs), with typical inlet and outlet gas temperatures of 612 and $912 \mathrm{~K}$ respectively [1].

Pellet-clad interaction (PCI) has been associated with fuel failures in a number of reactor systems [2-11]. Consequently, fuel designs have been altered [12, 13] and operating restrictions imposed $[3,14]$, the latter resulting in financial loss and a decrease in the ability for nuclear power to respond to our fluctuating energy demands. Increasing the fraction of our energy derived from low-carbon sources will inevitably cause an increase in demand for 
nuclear power plants to perform flexible operation and necessitate greater focus upon operational PCI limitations [15].

During the initial rise to power, non-uniform thermal expansion across the radius of the pellet produces thermal strains that cause the fuel pellets to crack [5, 14, 16, 17]. These cracks are predominantly radial and azimuthal and result in a number of pellet fragments $[16,18]$. Typically there are approximately eight radial cracks (in the $r-\theta$ plane) $[11,19,20]$ and between one and three cracks in the $(r-z)$ plane [21] in AGR fuel. Later, additional radial cracks can develop close to the pellet surface [22] as a result of power changes. Following the initial rise to power, sintering of the fuel pellet decreases its outer radius whilst matrix and gaseous fission product swelling causes the radius to increase. Overall, this results in the motion of the fuel pellets outwards, towards the cladding, over time.

Thermal and irradiation creep of the cladding causes its diameter to decrease and the cladding-fuel gap to reduce and eventually close [5]. Due to the use of stainless steel cladding, a smaller gap ( $25 \mu \mathrm{m}$ in an AGR compared to $80 \mu \mathrm{m}$ in a PWR) and higher coolant temperature, the gap closes much more rapidly in the AGR than the PWR system. During initial contact, only parts of the fuel pellet outer surface are in contact with the cladding and the pellet cracks are open; this is sometimes referred to as soft-PCI [21]. Later, the whole of the pellet outer surface is in contact with the cladding and the radial cracks close; this is sometimes referred to as hard-PCI [20]. Radial and azimuthal motion of the pellet fragments during both routine reactor operation and fault transients can result in stress concentrations in the cladding [4]. This mechanism is often referred to as pellet-clad mechanical interaction (PCMI) [23-25] and does not consider the role of aggressive fission products such as iodine [26].

PCI is therefore a complicated combination of physical, mechanical and metallurgical processes. To understand it better, a number of assessment methods have been developed, which include operational rules based upon experiments / operating limits and models within fuel performance codes [27]. Traditional fuel performance codes such as ENIGMA and TRANSURANUS have considered azimuthal slices of fuel discretised into a number of radial annuli. The slices are then weakly linked and so the models are sometimes referred to as 1.5 D models [28]. The finite element method and greater computing power has enabled fully coupled 2D models to be developed in either the $r-z$ [29-32] or $r-\theta$ planes [22, 33-35]. The 2D $(r-z)$ models are able to model an entire fuel pin but are unable to model the azimuthal opening of the fuel pellet cracks and associated stress concentrations. Meanwhile, the 2D ( $r-$ $\theta$ ) models neglect axial effects such as stress concentration at the pellet ends and progressive clad ratcheting due to the movement of pellet ends during power-cycling in AGR fuel. Finally, although entire fuel pins have been modelled by BISON [36, 37], 3D models [4, 14] are frequently only able to rapidly model a single cracked pellet or small stack of cracked pellets $[4,14,38-40]$.

The motion of fuel pellet fragments and the opening and closing of pellet cracks are introduced into fuel performance codes through either smoothed cracking models or empirical correlations based upon experimental data [5, 21, 41, 42]. Smoothed cracking models differ between fuel performance codes, but typically approximate cracks by significantly reducing the elastic modulus of the fuel either globally, or in the direction perpendicular to open cracks [5, 43-46]. 
'Relocation' is a term used to describe three broad phenomena [20] in LWR fuel pins. Firstly, the radial motion of pellet fragments towards the cladding reducing the pellet-clad gap [47] and therefore centre-line temperature. Secondly, the closing of pellet cracks following contact through a process known as 'relocation accommodation' [5]. Thirdly, the change in pellet crack surface morphology giving rise to the non-recoverable transfer of pellet free volume from the gap to the pellet bulk [42], causing a reduction in the macroscopic elastic modulus and thermal conductivity [45].

PELICAN is a finite element model for PCMI in thermal reactor fuel under development at Imperial College London [48, 49]. Previous work considered bonded cladding in the AGR system and the resultant short $(5 \mu \mathrm{m})$, benign, incipient clad bore crack on the inner surface of the cladding [48]. It relied upon EDF Energy's ENIGMA fuel performance code to determine the dimensions of the inner $11 / 12^{\text {th }}$ of the fuel pellet and the pin internal pressure and showed considerable sensitivity to the radial displacement of the pellet fragments. This lead to the realisation that more effort was needed to accurately model the motion of pellet fragments during reactor power transients.

This paper details the extension of PELICAN to model the entire $r-\theta$ mid-pellet plane in the AGR system. Three transients were considered:

1. The fuel undergoes a period of extended low power operation before returning to full power;

2. The fuel experiences a fault transient immediately following the return to full power;

3. The fuel experiences a fault transient without a previous period of low power operation.

(Note that the duration and power levels were chosen to reflect the non-availability of a single boiler in the AGR system out of a total of four.)

\section{Methodology}

\subsection{Model Construction}

PELICAN consists of a combination of an Abaqus finite element model and a series of userdefined subroutines. A number of models, within PELICAN, are available for physical properties of uranium dioxide fuel, stainless steel cladding and Zircaloy. These are selected by setting parameters in a separate fuel properties file.

Fig. 1 shows the geometry of finite element models created for PELICAN, together with the mesh applied to the cracked pellet model. They consist of:

- A cracked AGR fuel pellet, with 8 idealized radial cracks, together with stainless steel cladding.

- An un-cracked AGR fuel pellet, together with stainless steel cladding.

- A cracked BWR fuel pellet, with 8 idealized radial cracks, together with Zircaloy cladding. This model was used for thermal validation as described later.

In addition, models with an inter-crack angle between 5 and 120 degrees ( 3 and 72 cracks) were created to determine the effect of the number of radial cracks upon the stress concentration in the cladding. 'Idealized' cracks refer to straight radial cracks at uniform separation.

For the AGR simulations the fuel dimensions and enrichments are typical of those used in British reactors. The dimensions for the BWR simulation was based upon those used in Halden instrumented fuel assembly IFA-507, which included two sizes of pellet-clad gap [50]. 
A coolant pressure was applied to the outer surface of cladding. It had a magnitude of 4.1 $\mathrm{MPa}$ in the AGR simulations and 3.33 MPa for the Halden simulations. A variable internal pressure was applied to the internal surfaces, including the cracks; this is described in section 2.7. A radial power profile was applied to the pellet using Palmer's RADAR model [51], its inclusion into PELICAN has been discussed previously [49].

In PELICAN, the volumetric swelling strain, $\varepsilon_{s w, i}$, thermal strain, $\varepsilon_{t h, i}$, creep strain, $\varepsilon_{c r, i}$, elastic strain, $\varepsilon_{e l, i}$, and plastic strain, $\varepsilon_{p l, i}$, are considered; the total strain is calculated from the sum of these. For some physical phenomena, a number of materials models are available but for brevity only the default models used in this work are discussed.

\subsection{Thermal Expansion}

The instantaneous thermal expansion, $\alpha$, is a function of temperature shown in eq. 1 , where $\alpha_{1}, \alpha_{2}$ and $\alpha_{3}$ are fitted coefficients. The increment of thermal strain is calculated by integrating the instantaneous coefficient of thermal expansion with respect to temperature, $T$.

$\alpha=\alpha_{1}+\alpha_{2} T+\alpha_{3} T^{2}$

For uranium dioxide, the coefficients are given by Ainscough and Hedger [31, 52]; for stainless steel, by Bond [31, 53]; and for Zircaloy, by Harbottle and Donaldson [54]. For the cladding materials, $\alpha_{3}$ is set to zero.

\subsection{Volumetric Expansion}

Volumetric swelling in the fuel is the sum of terms relating to in-pile densification, matrix swelling, intra-granular fission product swelling and inter-granular fission product swelling. Volumetric swelling in cladding materials was not considered as this is not encountered in the AGR system.

By default, the in-pile densification model by White [55] is used in PELICAN, although models by Assmann \& Stehle [56, 57] and ESCORE are also available [58]. The White densification model is based upon data from fuel stack elongation experiments carried out at Halden and Harwell [59]. The fractional fuel porosity is partitioned into a proportion which can be sintered at a given temperature, of which a further proportion sinters more rapidly. The rate at which these proportions sinter is a function of temperature, burn-up and grainsize. The implementation of this model in PELICAN is discussed in more detail in [49].

The matrix swelling rate is assumed to be proportional to the local fission rate. In this work, it was assumed to be $2.5 \times 10^{-29}$ (fissions $\mathrm{m}^{-3}$ ) $^{-1}$ in BWR fuel [60] and in AGR fuel, $8.0 \times 10^{-3}$ per $\%$ atom burn-up [61]. The different units represent the different sources and methods of calculation.

By default, PELICAN utilises the gaseous fission product swelling model developed by Spino [62]; alternatively the MATPRO approach can be taken [58, 60]. Spino's model considers a population of gas atoms, the production rate of which is proportional to the fission rate. The gas atoms are initially dissolved into the matrix, but can migrate to, and be re-dissolved from, inter-granular and intra-granular bubbles. The volumetric gaseous swelling strain, is given by eq. 2; where $c_{g}$ is the density of dissolved gas atoms; $a$ is the lattice parameter, given by [63]; $r_{b}$ is the radius of intra-granular bubbles, assumed to be $0.216 \mathrm{~nm}$; $c_{b}$ is the intra-granular gas bubble density; $R_{b}$ is the inter-granular gas atom radius, calculated in the model and $C_{b}$, the inter-granular gas density. 
$\left(\frac{\Delta V}{V_{0}}\right)_{G}=\frac{c_{g} a^{3}}{4}+\frac{4 \pi}{3}\left(r_{b}^{3} c_{b}+R_{b}^{3} C_{b}\right)$

\subsection{Creep}

Both irradiation and thermal creep are modelled in uranium dioxide and Zircaloy. Irradiation creep is not considered in AGR stainless steel cladding. This is in part due to the lower neutron flux in AGRs compared to other reactor designs, but chiefly because of the considerably higher operating temperatures than in other reactor systems. This means that any irradiation component is insignificant compared to the thermal component.

The default creep model for uranium dioxide creep is that of Clough and Beatham [64]; alternatively, the models described for MATPRO [60] and BISON [58] can be used. The Clough and Beatham model takes the functional form given in eq. 3, with constants given in [31].The three terms account for a low stress component (a function of equivalent stress, $\sigma$, and temperature, $T$ ), an irradiation component (a function of fission rate, $\dot{F}$ ) and a power-law creep component (dependent upon the grain size, $G$ ); $P_{F}$ is a porosity correction factor and all other parameters constants.

$\dot{\varepsilon}_{c r, U O_{2}}=P_{F} C_{1} \sigma e^{-C_{2} / T}+C_{3} \dot{F} \sigma+\frac{P_{F} C_{4} \sigma^{C_{5}} e^{-C_{6} / T}}{G^{2}}$

The default creep model for Zircaloy is that of Donaldson [54]; alternatively, that of Wood and Watkins can be used [65]. The Donaldson model assumes that Zircaloy creep is isotropic and gives the total creep strain as the sum of four terms given in eq. 4, representing secondary irradiation creep, $\varepsilon_{S e, I r}$, secondary thermal creep, $\varepsilon_{S e, T h}$, transient creep, $\varepsilon_{T r}$, and primary creep respectively, $\varepsilon_{P r}$. Equations 5-9 define each term in Donaldson's creep model; $t$ is the total time and $\phi_{F}$ the fast neutron flux. The time-hardening hypothesis was applied and an effective time approach used, together with the Newton-Raphson method, to calculate increments of strain.

$$
\begin{aligned}
& \varepsilon_{c r, Z r}=\varepsilon_{S e, I r}+\varepsilon_{S e, T h}+\varepsilon_{T r}+\varepsilon_{P r} \\
& \varepsilon_{S e, I r r}=C_{7} \emptyset_{F} \sinh \left(C_{8} \sigma\right) e^{-C_{9} / T} t \\
& \varepsilon_{S e, T h}=C_{10}\left(\frac{\sinh (X \sigma)}{X}\right)^{2} e^{-C_{11} / T} t \\
& X=C_{11}+C_{12} e^{-C_{13} \int_{0}^{t} \emptyset_{F} d t} \\
& \varepsilon_{T r}=C_{14}\left(1-e^{-C_{15} \dot{\varepsilon}_{S e, T h} t}\right) \\
& \varepsilon_{P r}=C_{16} \sigma^{C_{17}} e^{-C_{18} / T} t^{1 / 3}
\end{aligned}
$$

The Nichols relation [66] for the creep strain in stainless steel, $\varepsilon_{C r, S S}$, is given by eq. 10, with parameters reported in [31]. The first term accounts for diffusion creep and the second for dislocation creep.

$$
\dot{\varepsilon}_{C r, S S}=C_{19} \sigma^{C_{20}} e^{-C_{21} / R T}+C_{22} \sigma^{C_{23}} e^{-C_{24} / R T}
$$




\subsection{Instantaneous Plasticity}

Plasticity is considered in the cladding materials but not uranium dioxide. The yield stress, $\sigma_{y}$, is given by eq. 11 in Zircaloy and 12 in stainless steel. It is a function derived by empirical correlations given in [48] and [61] of the temperature, the fast flux dose, $\theta_{F}$, in Zircaloy, and helium concentration $[\mathrm{He}]$ in stainless steel.

$$
\begin{aligned}
& \sigma_{y}=P_{0}+P_{1} T+P_{2}\left(\int_{0}^{t} \emptyset_{F} d t\right)^{P_{3}} \\
& \sigma_{y}=P_{4}\left(\frac{\int_{0}^{t} T d t}{t}\right)^{P_{5}}[\mathrm{He}]^{P_{6}} e^{-P_{7} / T}
\end{aligned}
$$

Strain hardening is incorporated through eq. 13; in Zircaloy, the linear term is set to zero. Note that the parameters $P_{8}-P_{10}$ differ between materials.

$\varepsilon_{P L}=P_{8}\left(\frac{\sigma}{\sigma_{y}}\right)^{P_{9}}+P_{10}$

\subsection{Elasticity}

The elastic properties are a function of temperature and in the case of uranium dioxide, porosity, $P$. The functional form of the Young's modulus, $E$, takes the form shown in eq. 14 with parameter values given by [67] and [55]; for cladding materials $E_{3}$ is set to zero.

$E=\left(E_{0}-E_{1} T-E_{2} T^{2}\right)\left(1-E_{3} P\right)$

Poisson's ratio for stainless steel is assumed to be 0.325 and 0.390 for Zircaloy [55]. For uranium dioxide, the shear modulus, $G$, given by eq. 15 (taken from [67]) is used to determine Poisson's ratio. All materials are assumed isotropic.

$G=\left(G_{0}-G_{1} T-G_{2} T^{2}\right)\left(1-G_{3} P\right)$

\subsection{Internal Pressure Calculation}

PELICAN does not currently have the ability to model fission gas release into the pin as at the low burn-ups currently modelled, fission gas release is negligible. The internal pressure is calculated by using the ideal gas law and assuming that the gas temperature is that of the cladding inner surface. This approximation made the simulations more stable and made little difference to either the time to contact or stress to the cladding. The total volume is adjusted for the clad inner radius, pellet outer radius and bore radius. The pellet crack volume is neglected; this approximation is more appropriate for AGR than LWR fuel due to the presence of the central bore in the AGR fuel.

\subsection{Gap \& Contact Modelling}

Following the approaches used in the URGAP [68, 69], GAPCON [70] and ENIGMA [55], heat transfer is assumed to be the result of three parallel mechanisms:

- Conductance within the fill gas, with a thermal conductance, $k_{g a s}$;

- Solid-solid conductance between surfaces in contact, with a thermal conductance, $k_{\text {contact; }}$;

- Radiation, with a thermal conductance, $k_{\text {rad }}$.

The total conductance is the sum of the three terms listed above. 
The thermal conductance within the fill gap is calculated using eq. 16. The gas thermal conductivity, $\lambda_{\text {gas }}$, is a function of temperature taken from the work of Hashimito [71] and is divided by a 'thermal gap'. This 'thermal gap', used for modelling heat transfer within the 'GAPCON' subroutine, is the sum of the gap determined by Abaqus, $d_{\text {mech }}$, the minimum gap size associated with the surface roughness, $d_{\min }$, (which takes the value given by Beyer et. al. [70]) and the gas jump distance, $d_{\text {jump }}$ (which takes the value used in ENIGMA [61]).

$k_{\text {gas }}=\frac{\lambda_{\text {gas }}}{\left(d_{\text {jump }}+d_{\text {min }}+d_{\text {mech }}\right)}$

The approach to calculating the gap conductance due to surface-surface contact was that described by Lassmann for the URGAP model [68, 69]. It takes the form given in eq. 17, where $P$ is the contact pressure between the surfaces; $\lambda_{a v}$ is the average thermal conductivity of the two surfaces; $R_{a v}$ is the average surface roughness; $H_{\min }$ is the lower of the Meyer hardness of the two surfaces and $k_{1}$ and $k_{2}$ are constants.

$h_{\text {contact }}=k_{1} R_{a v} \lambda_{a v}\left(\frac{P}{H_{\min } R_{a v}{ }^{2}}\right)^{k_{2}}$

The heat transfer through radiation is calculated by applying eq. 18 , where $\sigma_{S B}$ is the StefanBoltzmann constant; $T_{1}$ and $T_{2}$ are the temperatures of the two surfaces; and $\varepsilon$ the emissivity, assumed to be equal to 0.8. Radiative heat transfer was incorporated via the Abaqus contact formulation rather than the GAPCON subroutine. This was found to give more rapid convergence due to more effective coupling between the mechanical and thermal response.

$h_{\text {rad }}=\varepsilon \sigma_{S B} \frac{T_{1}^{4}-T_{2}^{4}}{T_{1}-T_{2}}$

Finite-sliding surface-surface interactions were used throughout, with a coefficient of friction of 0.2 between fuel pellet fragments and by default, 0.8 between the cladding and fuel. Previous work $[6,38,48]$ has shown the sensitivity to the coefficient of friction used between the cladding and fuel. The default value of 0.8 was chosen on the basis of the default assumption for AGR fuel made in ENIGMA. This is towards the upper range of experimental values for LWR fuel with a coefficient of friction between 0.4 and 0.6 considered more typical for PWR ramps [6]. To investigate the sensitivity to this value, simulations were run with coefficient of friction varying between 0.01 and 1.40 .

\subsection{Validation}

To validate the thermal response of the model, the centreline temperature predicted by PELICAN was compared to that measured by thermocouples installed in an instrumented fuel assembly irradiated at the Halden test reactor. The IFA507 experiment consisted of six pins of BWR fuel irradiated in stress relieved Zircaloy-2 cladding. The experiment is described in detail elsewhere [50]. The fuel pellets had two different diameters, resulting in wide and narrow gapped fuel pins, allowing the performance of the clad-fuel gap subroutine to be tested. In the experiment, only the narrow-gapped pins gave rise to clad-pellet contact and so only these are considered in this work. Validation was carried out against a detailed irradiation history out to a burn-up of approximately $15 \mathrm{GWd} / \mathrm{tU}$, together with thermocouple measurements at positions of peak rating. 
To validate the mechanical response of the model, the clad and pellet bore radii predicted by PELICAN were compared to that measured by post irradiation examination of an instrumented fuel assembly irradiated at the Halden test reactor. The pin was initially irradiated at Hinkley Point B and then transferred to Halden and encapsulated in a Zircaloy capsule. The bottom half of the pin was ramped and the top half not. Pins chosen were IFA 583_2_2 and IFA 583_4_15.

\subsection{Demonstration Simulations}

Three test transients were used to demonstrate pellet relocation in PELICAN (summarised in Fig. 2). These were a ramp to $150 \%$ power from full power; a ramp to $150 \%$ power from reduced power $(70 \%)$ and a period of reduced power operation with no ramp followed by a return to full power. In each case, the fuel was brought to full power of $20.1 \mathrm{~kW} \mathrm{~m}^{-1}$ and cladding temperature of $974.75 \mathrm{~K}$ over one day. The ramp was carried out at $7.5 \times 10^{6} \mathrm{~s}$ (approximately 3 months) after full power was reached. This time was chosen to be towards the end of a period of operation between refuelling outages at a station that doesn't refuel onload. The ramp lasted by default $100 \mathrm{~s}$. It was assumed that the coolant temperature remained unchanged during the ramp. For the simulations requiring a reduction in power, power was reduced to $70 \%$ over 10 hours and held at this level for $2.5 \times 10^{6} \mathrm{~s}$ (approximately 1 month). This represents a period of operation on three rather than four steam generators. The cladding surface temperature at reduced power was $882.75 \mathrm{~K}$ and the linear rating $14.1 \mathrm{~kW} \mathrm{~m}^{-1}$. In order to examine the effect of reduced power operation with no ramp, the power and temperature were returned to their full power values over $10 \mathrm{~h}$ and held for $2.5 \times 10^{6} \mathrm{~s}$. In addition the duration of the ramp was varied between 3 and 10,000 s. All simulations modelled transients when the fuel had a burnup of $1.5 \mathrm{GWd} \mathrm{tUO}_{2}{ }^{-1}$. This was sufficient time for the stresses in the cladding to condition to a steady state value and reflects the several months between refuelling programmes in an AGR.

The AGR cracked-pellet model had 13,950 nodes and 10,405 elements; the un-cracked model had 12,151 nodes and 9,629 elements. For the ramp from $70 \%$ power, the cracked pellet model took $18.3 \mathrm{~h}$ to run and the un-cracked model $13.4 \mathrm{~h}$. Simulations were carried out on a single Intel Xeon E5-1630 v3 $3.70 \mathrm{GHz}$ core, on a workstation with 32 GB of memory, running Ubuntu 14.04 and Abaqus 6.14-3 with Intel Fortran 64 Compilers (version 16.0.2.181 B). An extensive mesh convergence study was carried out. The LWR centre-line temperature was most sensitive to the element size in the bulk pellet; reducing the element size from 0.4 to $0.1 \mathrm{~mm}$ reduced the maximum temperature during the simulation by $4 \mathrm{~K}$. The maximum hoop stress recorded in the AGR cladding was most sensitive to the size of the element in the cladding ahead of the crack; reducing the element size from 10 to $2.5 \mu \mathrm{m}$ increased the stress by $3 \mathrm{MPa}$.

\section{Results}

\subsection{Validation}

Fig. 3 compares the fuel centre-line temperature predicted by PELICAN to that measured by thermocouples at the peak of each power cycling experiment for the thin walled pins of IFA507. Of the thirteen cycles, for which data were available, PELICAN predicted a temperature within the range measured on three occasions, under-predicted the temperature on six occasions and over-predicted on four occasions. The maximum over-prediction was by $69 \mathrm{~K}$ at $5 \mathrm{GWd} \mathrm{tUO}_{2}{ }^{-1}$ and the maximum under-prediction $49 \mathrm{~K}$ at $2 \mathrm{GWd} \mathrm{tUO}_{2}{ }^{-1}$; there was no overall trend of under or over-prediction with time. Contact between the cladding and pellet was first predicted by PELICAN during the ramp at $4 \mathrm{GWd} \mathrm{tUO}_{2}{ }^{-1}$. After this time, contact was predicted during power cycling but not the periods in between. 
Fig. 4 shows the clad and pellet bore radii predicted by PELICAN and measured by post irradiation examination. In both experiments, the ramp test increased the clad radius and decreased the bore radius. For pin IFA 583_2_2, the clad radius was under-predicted by 24 $\mu \mathrm{m}$ and for IFA $583 \_4 \_15$, over-predicted by $23 \mu \mathrm{m}$. For pin IFA $583 \_4 \_15$, the bore radius was under-predicted by $21 \mu \mathrm{m}$ and for IFA $583 \_2 \_2$, by $2 \mu \mathrm{m}$.

\subsection{Stresses within Fuel}

Fig. 5(a) shows that for both the cracked and un-cracked pellet, the radial stress was negligible and following contact the pellet remains in radial compression throughout the simulation. At the end of the initial ramp to power, the hoop and axial stresses were very similar at 475 and $470 \mathrm{MPa}$ respectively in the un-cracked pellet; the stress then decreased through creep relaxation. The peak hoop and axial stresses in the un-cracked pellet at the end of the ramp from $100 \%$ power were 560 and $550 \mathrm{MPa}$, whilst for the ramp from $70 \%$ power the values were 510 and $505 \mathrm{MPa}$. For both hoop and axial components, the peak tensile stresses were always found on the outer surface, whilst the inner surface remained compressive.

Modelling the pellet with eight radial cracks reduced the magnitude of the stress on both inner and outer pellet surfaces, in both the hoop and axial directions, compared to the uncracked pellet simulations. At the end of the initial rise to power, the hoop and axial stresses were reduced, compared to the un-cracked pellet, to 100 and $360 \mathrm{MPa}$. Following the ramp from $100 \%$ power, the hoop and axial stresses were also reduced compared to the uncracked model, to 100 and $385 \mathrm{MPa}$ respectively.

\subsection{Pellet Fragment Motion during Early Life}

Studying Fig. 6a it is possible to identify the onset of soft-PCI, in the cracked pellet model, at around $30.0 \mathrm{~h}$. This was followed by a period of soft-PCI lasting around $2.8 \mathrm{~h}$, by which time full contact was made with the pellet outer surface.

Fig. $6 \mathrm{~b}$ shows the closure of the pellet-clad gap during start up and the following $24 \mathrm{~h}$. The maximum gap was larger for the un-cracked pellet at $45.6 \mu \mathrm{m}$, compared to $40.5 \mu \mathrm{m}$ for the cracked pellet. Following contact the cladding and pellet remained in contact throughout the rest of the simulation. Initial contact at the pellet cracks was $1.8 \mathrm{~h}$ earlier in the cracked model. This was due to the additional radial displacement of the pellet outer surface shown in Fig. 6a. Although not shown it is worth noting that the maximum temperature reached during the rise to power was therefore slightly higher for the un-cracked pellet at $1330 \mathrm{~K}$ (compared to $1322 \mathrm{~K}$ for the cracked pellet). The temperature then decreased for both models to the same value of $1278 \mathrm{~K}$ when pellet-clad contact occurs.

Fig. 6c shows the changes in the width of the cracks at the pellet inner and outer surface. It shows that during creep-down of the cladding onto the pellet, the decreasing pellet temperature caused the cracks on both surfaces to continue to open. Following initial contact between the cladding and pellet, the cracks at the pellet bore closed completely and those at the surface closed partially. This closure of pellet cracks at the bore is a phenomenon associated with soft-PCI. The cracks at the pellet surface closed by $3.4 \mu \mathrm{m}$ during the $1.8 \mathrm{~h}$ period of soft-PCI and close by only another $1.3 \mu \mathrm{m}$ during the following 86 days at full power. The model is therefore considered to be able to predict part of the relocation accommodation phenomenon, the full phenomenon occurs due to the $3 \mathrm{D}$ motion of the pellet fragments. 
Fig. 6a shows the pellet outer radius during and the following $24 \mathrm{~h}$. After reaching full power at $24 \mathrm{~h}$, the pellet radius decreased due to the reduction in thermal strain with temperature during creep down. The pellet radius reduced more slowly for the cracked model until the onset of soft-PCI, when the pellet radius decreased rapidly by $4.6 \mu \mathrm{m}$ over a few hours. Fig. $6 \mathrm{~d}$ shows that the bore radius for the cracked and un-cracked models during early life. Following full power at $24 \mathrm{~h}$, the bore opened in the cracked model and closed in the uncracked model. During the period of soft-PCI (cracked model) the bore closed by $4.4 \mu \mathrm{m}$. The bore of the un-cracked model remained smaller than the cracked model throughout the simulation.

The temperature of the cladding at the end of the initial rise to power was $981 \mathrm{~K}$. The temperature of the pellet outer surface was $1037 \mathrm{~K}$ for the cracked pellet and $1041 \mathrm{~K}$ for the un-cracked pellet; at the pellet bore, the temperatures were 1325 and $1326 \mathrm{~K}$ respectively.

\subsection{Cladding Response to Transients}

Fig. 7 summarises the stress in the cladding during key points in the simulations. Fig. 8a shows that generally, the hoop stress in bulk cladding (in the centre of the cladding, well away from the radial pellet cracks) was the same for the bulk cladding in the case of cracked and un-cracked pellets. The hoop stress ahead of the pellet crack was generally greater in magnitude than in bulk cladding. During the ramp from full power (Fig. 8b), the hoop stress in the bulk cladding increased from $-1 \mathrm{MPa}$, in bulk cladding, to $132 \mathrm{MPa}$ in the un-cracked model and $123 \mathrm{MPa}$ in the cracked model. Ahead of the radial pellet crack, the hoop stress increased to $217 \mathrm{MPa}$ by the end of the transient. During the ramp from low power (Fig. 8c), the cladding hoop stress in the un-cracked model increased to $209 \mathrm{MPa}$ over the first $89 \mathrm{~s}$ of the $100 \mathrm{~s}$ uprate before increasing more slowly to $211 \mathrm{MPa}$ by the end of the transient. The bulk cladding hoop stress increased to 173 over the whole transient in the cracked model, with a slower increase after around $70 \mathrm{~s}$. The hoop stress ahead of the pellet crack increased to $281 \mathrm{MPa}$ during the transient, the most rapid rise was between 8 and $30 \mathrm{~s}$.

The pattern of similar hoop stresses in the bulk cladding of the cracked / un-cracked models and a greater magnitude stress ahead of the radial crack was broken during the period at reduced power (Fig. 8d). During the down-rate to reduced power (0 days on Fig. 8 d), the hoop stress in the bulk cladding of the un-cracked model increased to $2.7 \mathrm{MPa}$, whilst in the cracked model the hoop stress became compressive at $-42.5 \mathrm{MPa}$. Ahead of the pellet crack, the hoop stress in the cladding decreased less to $-26.9 \mathrm{MPa}$. The difference in the hoop stress in bulk cladding was due to the greater decrease in the pellet outer radius during the down rate in the cracked pellet model. This resulted in the compressive hoop stress in the cracked model and tensile in the un-cracked model. The lower magnitude stress in the cladding ahead of the pellet crack, during the hold at full power, compared to bulk cladding was a result of previous creep in the cladding at that location. The peak in the hoop stress in the cladding at the same location, at 30 days, was a result of the pellet cracks opening during the uprate from $70 \%$ to full power.

Table 1 reports the changes in creep strain, in bulk cladding, surrounding both the cracked and un-cracked pellet, together with the creep strain in the cladding ahead of the radial pellet cracks. The ramp from low power was much less damaging than that from high power. Ahead of the radial crack, the creep strain increased by $0.254 \%$ during the ramp from full power and by only $0.029 \%$ during the ramp from $70 \%$ power. The strain was also strongly concentrated at positions above radial pellet cracks. The creep strain accrued in bulk cladding 
during the ramps was an order of magnitude lower than ahead of the radial pellet cracks. Finally, compared to the pre-transient value, the creep rate increased ahead of the radial cracks during the 10 days following the return to full power, but not in the bulk cladding of the cracked model, where the creep rate reduced. This can be explained by the partial closure of the pellet cracks following the uprate in power reducing the hoop stress in the cladding at this point.

\subsection{Effect of Ramp Duration}

Fig. 9a shows the peak hoop stress measured during the ramp for each model in both bulk cladding and ahead of the pellet crack. For the cracked pellet model, the maximum peak stresses were found for the $30 \mathrm{~s}$ ramp of $133 \mathrm{MPa}$ in bulk cladding and $224 \mathrm{MPa}$ ahead of the pellet crack. For the un-cracked pellet model, the maximum peak stress of $132 \mathrm{MPa}$ was found for $100 \mathrm{~s}$ ramp. As shown in Fig. 9b, the creep strain accrued in the cladding increased with ramp duration; the $3 \mathrm{~s}$ ramp gave rise to negligible creep strain in both models at all locations. For the $10,000 \mathrm{~s}$ ramp, the creep strain in bulk cladding was $0.06 \%$ for the uncracked model and $0.07 \%$ for the cracked model. The larger increase in the creep strain ahead of the radial pellet crack (seen in Fig. 9b) is a result in the larger stress (Fig. 8a) whilst the larger creep strain with ramp duration is mainly the result of a longer period of time over which creep occurred.

\subsection{Sensitivity to Coefficient of Friction}

Fig. 10a shows that increasing the coefficient of friction increased the peak hoop stress in the cladding ahead of the radial crack. Increasing the coefficient of friction from 0.01 to 1.4 increased the hoop stress by a factor of 2 from 121 to $242 \mathrm{MPa}$. The default coefficient of friction of 0.8 gave a stress of $217 \mathrm{MPa}$. A similar trend was seen in the creep strain accrued at the same position (Fig. 10b). At the beginning of the ramp, the creep strain increased from 0.91 to $3.05 \%$ over the range of coefficients of friction investigated. The creep strain accrued during the ramp itself increased from $0.02 \%$ to $0.50 \%$.

\subsection{Sensitivity to Angle between Radial Pellet Cracks}

Fig. 11a shows that decreasing the angle between radial cracks from 120 to $5^{\circ}$ (i.e. increasing the number of radial cracks in the pellet from 3 to 72) increased the radial displacement of the pellet surface during the ramp from full power from 9.2 to $11.5 \mu \mathrm{m}$. Conversely, it decreased the pellet crack tip opening displacement from 17.3 to $1.0 \mu \mathrm{m}$. Fig. $11 \mathrm{~b}$ shows that decreasing the angle between cracks over the same range reduced the hoop stress in the cladding ahead of the radial crack from 420 to $364 \mathrm{MPa}$ and on the outer surface mid-way between two cracks from 249 to $182 \mathrm{MPa}$. This had the effect of reducing the creep strain in the cladding ahead of the radial crack from 0.48 to $0.12 \%$ (see Fig. 11c). Relative sliding of the pelletpellet crack surface was not observed and the model was not found to be sensitive to the coefficient of friction applied between the pellet fragments.

\section{Discussion}

Comparing the temperature predicted by PELICAN to those measured in IFA 507, for narrow-gapped rods, showed a good agreement. The spread of measured values demonstrating the difficulty of making these measurements in reactor. PELICAN maintained an agreement to within $70 \mathrm{~K}$ between the experimental mean, with just under half of the centreline temperature predictions within the spread of experimental data, around a quarter under and a quarter over (see Fig. 3). Sheppard gives [50] a calibration error in the fuel channel rating of $4.5 \%$ and an error in the flux profile of $2.0 \%$ giving a total error of $6.5 \%$. 
Given a temperature drop across the pellet of around 1,300 K, during power ramps, an uncertainty in the temperature measurements of around $85 \mathrm{~K}$ is to be expected.

Power ramps after $4 \mathrm{GWd} \mathrm{tUO}_{2}^{-1}$ burn-up resulted in contact between the cladding and pellet, whilst those with lower burn-up did not. If there were any systematic over prediction of the centreline temperature before regular contact, this would suggest that the gap size was being over predicted; neither this nor the converse were the case. It can therefore be argued that the gap and therefore swelling and heat transfer was predicted accurately by PELICAN. Similarly, a systematic under or over prediction following contact would reflect poor modelling of the thermal conductivity within the pellet and again this was not the case.

Again, validation against the cladding and pellet bore strains was satisfactory (Fig. 4). The correct trend with ramping of increase in radius at the clad and decrease at the bore was predicted. In one pin, the clad radius was over-predicted by $24 \mu \mathrm{m}$, and the other it was under-predicted by a similar amount.

Centre-line temperature data during irradiation is not readily available for AGRs fuel. We consider the thermal validation appropriate since the fuel temperatures in the central regions of the pellet are similar in AGRs and LWRs.

The stresses within the pellet were dominated by the radial temperature profile and axial constraint applied. At full power, the pellet was around $300 \mathrm{~K}$ hotter at the inner than outer surface, leading to greater thermal expansion at the bore compared to the outer surface. Axial constraint, approximated here by generalised plane strain, led to compressive axial and hoop stresses at the bore and tensile stresses at the outer surface whilst at power. Stresses of the order 500-600 MPa in the un-cracked pellet are more than sufficient to crack the pellet given a typical fracture stress of un-irradiated $\mathrm{UO}_{2}$ in the range 150-250 $\mathrm{MPa}$ [72]. We can therefore expect a fuel pellet to crack both axially and radially at the outer surface and this is supported by both post irradiation examination [73] and previous models [16].

This work models highly idealized radial pellet cracks. These are assumed to develop during the initial rise to power, which is supported by Mella and Wenman [16]. Hoop stresses of 100 $\mathrm{MPa}$ in the cracked pellet fragments, at the end of the initial rise to power (see Fig. 5), suggest that further cracking is unlikely and supports the choice of eight radial cracks as a best estimate. The axial stress of $360 \mathrm{MPa}$ on the outer surface suggests that the stress relaxation caused by radial crack growth is unlikely to be sufficient to prevent axial cracks from forming on the pellet outer surface. Again this is seen in the explicit crack modelling work, where an axial crack forms [14]. At the end of the ramp from $70 \%$ power, the maximum hoop stress on the outer surface of the pellet was $125 \mathrm{MPa}(25 \mathrm{MPa}$ greater than during the ramp from $100 \%$ ). However, this is unlikely to cause more new radial cracks to form, although micro-cracking on the pellet surface might be possible.

During the initial rise to power, the cracked pellet fragments relocated radially outwards and the pellet outer surface radial displacement is therefore greater for the cracked pellet (Fig 6a). In addition, the cracks at the pellet outer surface opened (Fig. 6c). This decreased the cladpellet gap by $5.1 \mu \mathrm{m}$ compared to the un-cracked case (Fig. 6b) and reduced the pellet centreline temperature by a maximum of $8 \mathrm{~K}$. Between $24 \mathrm{~h}$ (the end of the raise to power) and 30h (initial pellet-clad contact in the cracked model) the clad crept back down onto the pellet, the pellet cooled due to the reduced pellet-clad gap and cracks began to open at the 
pellet bore (Fig. 6d). At the same time, the bore continued to increase in radius in the cracked model and reduced in radius in the un-cracked model.

Initial contact between the cladding and pellet was made at the pellet crack mouth at $29.8 \mathrm{~h}$. The location of the position of initial contact was the result of the thermal expansion of the pellet fragment. This saw an initial rapid decrease in the pellet radius (Fig. 6a) over around two hours, associated with closure of the cracks at the pellet bore and partial closure at the pellet surface (Fig. 6c). This period is often referred to as 'soft-PCI' and can be associated with recovery of some of the radial displacement associated with the pellet fragment relocation (relocation accommodation). It is notable that the cracked pellet model can capture this behaviour.

It should be noted that PELICAN is a $2 \mathrm{D}(r-\theta)$ model, appropriate to the pellet mid-plane and the hour-glassing effect due to the thermal gradient and pellet cracking is not modelled. This can be justified as, in the AGR context, as clad bore cracks have been observed along the whole pellet length and the PCI of interest is not therefore limited to pellet ends.

The slow closure of the pellet cracks at the outer surface, during steady state operation, caused the hoop stress in the cladding ahead of the crack to be more compressive than in bulk cladding (Fig 8a). The greater magnitude hoop stress above radial cracks caused the creep strain to rise more steeply here (Table 1). The similar stresses seen in bulk cladding in the two models can be explained by the similar radial displacement during the period of hardPCI. The greater total creep strain in the un-cracked model was a result of the reduced initial radial displacement of the pellet during the initial rise to power due to a lack of pellet relocation towards the cladding. Whilst pellet crack closure as a result of relocation accommodation was observed, the non-recoverable effect of crack 'mis-fit' and the effect of any creep recovery are not considered.

During the power ramps, whether from 70 or $100 \%$ power, the cracks at the pellet surface opened once more. This increased the hoop stress ahead of the pellet crack (Fig 8c-d) and therefore the creep strain in the cladding. The accrual of cladding creep strain during operational transients (detailed in Table 1) is of interest in the AGR system since it is considered the dominant mechanism for PCI driven crack growth in the cladding and therefore a possible source of fuel failures. The ramp from $100 \%$ power produced a creep strain of $0.254 \%$, ahead of the radial pellet cracks. This should be compared to the $0.020 \%$ strain accrued at this point in the 10 days prior to the reduction in power to $70 \%$, each day at full power therefore has an equivalent worth of $0.002 \%$ creep strain. The ramp from 100 to $150 \%$ power increased the creep strain ahead of the pellet cracks by an amount equivalent to 127 days full power operation whilst the ramp from 70 to $150 \%$ power accrued only 14.5 days worth of creep strain due to the lower coolant temperature meaning that the thermal creep was lower.

Compared to steady state operation, spending thirty days at reduced power increased the total creep strain accrued in the cladding ahead of the pellet cracks from 0.082 to $0.093 \%$, but reduced it from 0.020 to $0.004 \%$ in the un-cracked model. The reduced accrual in the uncracked model was due to the lower burn-up and hence reduced pellet swelling; the increased accrual in the cracked model was due to pellet motion. This demonstrates the importance of modelling relocation and relocation accommodation when calculating the creep strain resulting from a transient. A power manoeuvre in which the creep strain in cladding 
surrounding an un-cracked pellet would be predicted to be significantly reduced has been predicted to increase the creep strain ahead of radial cracks.

Before carrying out this work, it was expected that reducing the ramp duration would increase the opening of the pellet cracks due to the relative absence of creep and volumetric swelling in the fuel. This would in turn increase the cladding hoop stress ahead of the crack tip. The effect upon the creep strain in the cladding above radial pellet cracks would then be a competition between the increased stress and decreased time. This work has shown a peak in the stress in the cladding for ramps of an intermediate length of 30-100 s (see Fig. 9a). It should be noted that the range of coolant temperatures and fuel ratings encountered within the AGR system is greater than for other reactor designs and therefore, the maximum hoop stress is likely to vary in magnitude and timing across different fuel elements. It is not however surprising that Fig $9 \mathrm{~b}$ shows an increased accrual of creep strain with ramp duration.

It was found that increasing the coefficient of friction increased both the hoop stress in the cladding ahead of the radial crack in the pellet and the creep strain at the same point. The correct coefficient of friction to apply is difficult to determine experimentally and fuel performance codes typically use a value ranging from 0.4 to 1.2 . This gives a range of values of the accrued creep strain during the ramp of 0.10 to $0.40 \%$ around a default value of $0.25 \%$. Given this range of values, PELICAN, like other fuel performance codes, is therefore currently of more use in predicting the comparative effect of changes in fuel behaviour rather than the absolute value of the creep strain accrued in the cladding.

Generally, decreasing the angle between cracks decreased the azimuthal opening of the pellet cracks and increased the amount of radial pellet displacement towards the cladding. Nuclear fuel performance codes frequently assume that the number of radial pellet cracks increases as a power of 2 . The logic for this assumption is that any transient giving rise to pellet cracking will split each fragment in half. Fig. 11b shows that increasing the number of cracks beyond eight (reducing the angle between cracks to below $45^{\circ}$ ) reduced the hoop stress on the pellet outer surface by only around $20 \mathrm{MPa}$. Given that the outer surface pellet hoop stress for the power ramp modelled remained well above the fracture stress (400 c.f. 150-250 MPa) for all of the numbers of cracks modelled, it can be argued that the ramp would be likely to introduce a very large number of small cracks on the outer surface of the pellet. Fig. 11a suggests however, that as the number of radial cracks close to the surface increases, the pellet opening is likely to decrease and the stress concentration in the cladding decrease, giving rise to a reduced accrual of creep strain ahead of each radial crack (Fig. 11c). This has been suggested as one of the mechanisms, in addition to enhanced visco-plasticity, for the reduction of PCI in doped fuels for LWRs [74-76].

\section{Conclusions}

1. Compared to an un-cracked model of pellet, pellet fragment relocation produces a significant additional radial displacement at the pellet surface of a cracked pellet during the initial rise to power.

2. The use of a cracked pellet model was shown to be able to capture the 'soft-PCI' behaviour upon initial contact.

3. The further slow closure of pellet cracks during steady state operation gave rise to a more compressive stress ahead of radial pellet cracks and a greater creep rate than in bulk cladding. 
4. During a ramp from full power to $150 \%$ power, opening of the pellet cracks increased the hoop stress in the cladding ahead of the radial cracks by a factor of 1.6 compared to an un-cracked model. This behaviour is associated with 'hard-PCI'.

5. The modelling of PCI was very sensitive to the coefficient of friction used whilst showing little sensitivity to the number of radial pellet cracks. Increasing the number of cracks from 4 to 24 reduces the stress on the cladding by $14 \%$, whilst changing the coefficient of friction from 0.4 to 1.4 increases the stress by $35 \%$.

6. A maximum in the peak stress ahead of pellet cracks was seen for the $30 \mathrm{~s}$ ramp in the cracked pellet model.

\section{Acknowledgements}

Thomas Haynes would like to thank correspondence from Dr John Shea (formerly of EDF Energy) and Dr Ian Palmer (formerly of the UK National Nuclear Lab); technical support from EDF Energy's Fuel Group at Barnwood; insights from Dr Susan Morgan of the UK National Nuclear Lab, as well as the financial support of both EDF Energy and the EPSRC. Mark Wenman acknowledges financial support for the work by EPSRC and EDF Energy.

\section{Figure Captions}

1. Finite element models created for PELICAN. They consist of: (a) A cracked AGR fuel pellet, with 8 radial cracks, together with stainless steel cladding; (b) An uncracked AGR fuel pellet, together with stainless steel cladding; (c) A cracked BWR fuel pellet, with 8 radial cracks, together with Zircaloy cladding (used for thermal validation) and (d) The mesh applied to the 8-cracked pellet; the mesh applied to the un-cracked pellet is the same as that away from the pellet-pellet crack in the cracked model.

2. A schematic of the linear rating (a) and cladding surface temperature (b) applied to PELICAN for the ramp from high (100\%) power, reduced power $(70 \%)$ operation and ramp from low power.

3. A comparison of the pellet centre-line temperature predicted by PELICAN and measured by thermocouples on three narrow gapped instrumented fuel pins during the early irradiation of IFA-507. Error bars show the range of values recorded.

4. The impact of power ramping upon the clad and pellet bore radii at the end of experiment IFA 583_2_2 (a) and IFA 583_4_15 (b).

5. The radial, hoop and axial stress in the cracked and un-cracked fuel pellet at various points through the simulation. The magnitude of the crack opening has been multiplied by a factor of 100 and the pellet shapes should be regarded as being schematic.

6. The mechanical response of the cracked and un-cracked pellet during the end of the initial raise to power and contact, including: (a) The pellet outer radius; (b) The cladpellet gap; (c) The width of the pellet cracks at the pellet outer surface and bore and (d) The pellet bore radius.

7. 
The radial, hoop and axial stress in the cladding at various points through the simulation.

8. The hoop stress in the cladding surrounding the cracked and un-cracked pellet during: (a) The hold at full power; (b) The ramp from 100\% power; (c) The ramp from $70 \%$ power and (d) The reduction to $70 \%$ power and subsequent return to $100 \%$ power.

'Bulk cladding' refers to a position in the cladding well away from the pellet cracks and 'crack tip' refers to a position in the cladding immediately ahead of a pellet crack.

9. The impact of the competing effects of the crack opening speed and time at elevated stress resulting from varying the ramp duration upon: (a) The peak cladding hoop stress during a ramp from $100 \%$ power and (b) The cladding creep strain accrued during the ramp.

10. The effect of the coefficient of friction used in the interaction between the cladding and pellet upon: (a) The peak hoop stress in the cladding ahead of a radial pellet crack during the up-rate and (b) The creep strain accrued prior to and at the end of the uprate at the same location.

11. The effect of changing the angle between cracks (i.e. the number of radial pellet cracks) upon: (a) The pellet outer surface and crack tip opening displacement during the ramp; (b) The peak hoop stress during the ramp in the cladding and the pellet and (c) The creep strain in the cladding ahead of the radial crack at the end of the transient.

\section{Table Caption}

- The creep strain accrued in the cladding ahead of the radial pellet cracks, in bulk cladding (well away from radial cracks) and in the un-cracked model during each stage of the simulations.

\section{References}

1. Nonbol, E., Description of the Advanced Gas Cooled Type of Reactor (AGR). Riso National Laboratory, Roskilde, Denmark, 1996. NKS/RAK-2(96)TR-C2.

2. Cox, B., Pellet-clad interaction (PCI) failures of zirconium alloy fuel cladding - a review. Journal of Nuclear Materials, 1990. 172: p. 249-292.

3. Yagnik, S.K., D.J. Sunderland, and B.C. Cheng, Effect of PWR re-start ramp rate on pelletcladding interaction. Pellet-Clad Interaction in Water Reactor Fuels Transactions, Aix-enProvence, 2004: p. 63-77.

4. Michel, B., J. Sercombe, and G. Thouvenin, A new phenomenological criterion for pelletcladding interaction rupture. Nuclear Engineering and Design, 2008. 238(7): p. 1612-1628.

5. Bernaudat, C., Mechanical behaviour modelling of fractured nuclear fuel pellets. Nuclear Engineering and Design, 1995. 156: p. 373-381.

6. Brochard, J., et al., Modelling of Pellet Cladding Interaction in PWR fuel. Transactions, SMIRT 16, Washington DC, 2010. 1314.

7. Wood, J.C., PCI-OGRAMS: application of CANDU fuelogram methodology to PCl data from light water reactors. IAEA Specialists Meeting on Power Ramping and Power Cycling of Water Reactor Fuels; Arles, France, 1979. 17: p. 1-8.

8. Van Uffelen, P., et al., Review of operational requirements with respect to PCMI in a VVER and the corresponding developments in the transuranus code. Pellet-Clad Interaction in Water Reactor Fuels Transactions, Aix-en-Provence, 2004: p. 53-62. 
9. Smirnov, A.V., et al., Pellet-Cladding Interaction In VVER Fuel Rods. Pellet-Clad Interaction in Water Reactor Fuels Transactions, Aix-en-Provence, 2004: p. 231-240.

10. Bond, G.G. and A.G. Uglow, A comparison between reactor experiments and sleuth-seer code predictions of pellet-clad interactions on AGR fuel pins. Nuclear Engineering and Design, 1980. 56: p. 135-141.

11. Shea, J.H., et al., Modelling the effects of flexible operation on AGR fuel integrity. TopFuel '97 Transactions, 1997. 5: p. 176-183.

12. Gittus, J.H., Theoretical analysis of the strains produced in nuclear fuel cladding tubes by the expansion of cracked cylindrical fuel pellets. Nuclear Engineering And Design, 1972. 18: p. 6982.

13. Armijo, J.S. and Z. Abdullahi, Pellet cladding interaction fuel failures during anticipated perational occurrences in boiling water reactors. United States Nuclear Regulatory Commission Report, 2009: p. 1-22.

14. Michel, B., et al., 3D fuel cracking modelling in pellet cladding mechanical interaction. Engineering Fracture Mechanics, 2008. 75(11): p. 3581-3598.

15. Beguin, S., PCl-related constraints on EDF PWRs and associated challenges. Pellet-Clad Interaction in Water Reactor Fuels Transactions, Aix-en-Provence, 2005: p. 53-62.

16. Mella, R. and M.R. Wenman, Modelling fracture of nuclear fuel pellets during a power transient using peridynamics. Journal of Nuclear Materials, 2015. 467: p. 58-67.

17. Morgan, S., et al., Understanding advanced gas-cooled reactor (CAGR) fuel using metallography. TopFuel 2012 Transactions, 2012: p. 515-519.

18. Huang, H.S., B. and J. Hales, Discrete element method for simulation of early-life thermal fracturing behavior in ceramic nuclear fuel pellets. Nuclear Engineering and Design, 2014. 278: p. 515-528.

19. Williford, R.E.L., D.D. and C.L. Mohr, A model for the effective thermal and mechanical properties of cracked $\mathrm{UO}_{2}$ pellets. Nuclear Technology, 1981. 56: p. 340-350.

20. Walton, L.A. and D.L. Husser, Fuel Pellet Fracture and Relocation. Water Reactor Fuel Element Performance Computer Modelling, 1983: p. 115-152.

21. Oguma, M., Cracking and relocation behaviour of nuclear fuel pellets during rise to power. Nuclear Engineering and Design, 1983. 76: p. 35-45.

22. Sercombe, J., R. Masson, and T. Helfer, Stress concentration during pellet cladding interaction: Comparison of closed-form solutions with $2 D(r, \vartheta)$ finite element simulations. Nuclear Engineering and Design, 2013. 260: p. 175-187.

23. Kim, Y.M., et al., Assessment of cladding relaxation and PCMI models in INFRA. Pellet-Clad Interaction in Water Reactor Fuels Transactions, Aix-en-Provence, 2004: p. 425-437.

24. Wiesenack, W. and T. Tverberg, PCMI of high burn-up fuel as manifested by different types of instrumentation and measurements in the Halden reactor experimental programme. PelletClad Interaction in Water Reactor Fuels Transactions, Aix-en-Provence, 2004: p. 321-332.

25. Suzuki, M., H. Saitou, and T. Fuketa, RANNS code analysis on the local mechanical conditions of cladding of high burnup fuel rods under PCMI in RIA-simulated experiments in NSRR. Nuclear Science and Technology, 2006. 43(9): p. 1097-1104.

26. Rossi, M.L. and C.D. Taylor, First-principles insights into the nature of zirconium-iodine interactions and the initiation of iodine-induced stress-corrosion cracking. Journal of Nuclear Materials, 2015. 458: p. 1-10.

27. Boyd, W.A. and G. Mangham, A Westinghouse Local Fuel Duty PCI Risk Monitor and Analysis Tool. TopFuel 2015 Transactions, 2015. 1: p. 303-312.

28. Sunderland, D.J., Reflections on 25 years of LWR fuel modeling, challenges and contemporary issues. Nuclear Science and Technology Interaction Program (NSTIP), ORNL, 2011.

29. Williamson, R.L., Enhancing the ABAQUS thermomechanics code to simulate multipellet steady and transient LWR fuel rod behavior. Journal of Nuclear Materials, 2011. 415(1): p. 74-83. 
30. Soba, A. and A. Denis, Simulation with DIONISIO 1.0 of thermal and mechanical pelletcladding interaction in nuclear fuel rods. Journal of Nuclear Materials, 2008. 374: p. 32-43.

31. Mella, R. and M.R. Wenman, Axisymmetric whole pin life modelling of advanced gas-cooled reactor nuclear fuel. Journal of Nuclear Materials, 2013. 437(1-3): p. 154-165.

32. Liu, R.P., A., W. Zhou, and P.K. Chan, Multiphysics coupled modeling of light water reactor fuel performance. Progress in Nuclear Energy, 2016. 91: p. 38-48.

33. Walker, S.P., A. Yu, and R.T. Fenner, Pellet-clad mechanical interaction: Pellet-clad bond and strain relief. Nuclear Engineering and Design, 1992. 138: p. 403-408.

34. Yu, A., S.P. Walker, and R.T. Fenner, Pellet-clad bonding during PCMI. Nuclear Engineering and Design, 1990. 121: p. 53-58.

35. Marchal, N., C. Campos, and C. Garnier, Finite element simulation of Pellet-Cladding Interaction (PCI) in nuclear fuel rods. Computational Materials Science, 2009. 45: p. 821-826.

36. Tonks, M.R., Modelling Reactor Fuel Material Behavior Based on Microstructure Rather Than Burn-Up. NUMAT - The Nuclear Materials Conference, Montpellier (France), 7-10th November 2016, 2016. Plenary Presentation.

37. Hales, J. and B.W.W. Spencer, R.L., Multidimensional modelling options in the BISON fuel performance code. NUMAT - The Nuclear Materials Conference, Montpellier (France), 7-10th November 2016, 2016. Poster Presentation: p. P2.88.

38. Sercombe, J., I. Aubrun, and C. Nonon, Power ramped cladding stresses and strains in 3D simulations with burnup-dependent pellet-clad friction. Nuclear Engineering and Design, 2012. 242: p. 164-181.

39. Williamson, R.L., et al., Multidimensional multiphysics simulation of nuclear fuel behavior. Journal of Nuclear Materials, 2012. 423(1-3): p. 149-163.

40. Baurens, B., et al., 3D thermo-chemical-mechanical simulation of power ramps with ALCYONE fuel code. Journal of Nuclear Materials, 2014. 452: p. 578-594.

41. Lassmann, K.B., H., Modelling the fuel rod behaviour and recent advances of the TRANSURANUS code. Nuclear Engineering and Design, 1988. 106: p. 291-313.

42. Jernkvist, L.O., A continuum model for cracked $\mathrm{UO}_{2}$ fuel. Nuclear Engineering and Design, 1997. 176: p. 273-284.

43. Shea, J.H., A Review of the ENIGMA Fuel Pellet Mechanical Model. British Energy, 2002. E/REP/REAC/0060/GEN/02: p. 1-12.

44. Williford, R.E. and D.D. Lanning, Cracked Fuel Mechanics. Water Reactor Fuel Element Performance Computer Modelling, 1983. 1: p. 153-186.

45. Williford, R.E., D.D. Lanning, and C.L. Mohr, A model for the effective thermal and mechanical properties of cracked $\cup_{2}$ pellets. Nuclear Technology, 1981. 56: p. 340-350.

46. Guicheret-Retel, V., et al., Elastic and viscoplastic pellets fragmentation modeling using an axisymmetrical 1D finite element code. Nuclear engineering and Technology, 2004. 232: p. 249-262.

47. Guicheret-Retel, V., et al., Modelling 3-D Mechanical Phenomena in a 1-D Industria; Finite Element Code : Results and Perspectives. Pellet-Clad Interaction in Water Reactor Fuels Transactions, Aix-en-Provence, 2004: p. 453-463.

48. Haynes, T.A., et al., Modelling pellet-clad mechanical interaction during operational transients in bonded nuclear fuel. Journal of Nuclear Materials, 2015. 465: p. 280-292.

49. Haynes, T.A., et al., Finite element modelling of pellet-clad interaction during operational transients. TopFuel 2015 Oral Transactions, 2015: p. 62-71.

50. Sheppard, D.O., Data Report IFA-507 From B.O.L. to $15.4 \mathrm{MWd} / \mathrm{kg} U \mathrm{OO2}$. OECD Halden Reactor Project, 1982. HWR-74.

51. Palmer, I.D., K.W. Hesketh, and P.A. Jackson, A Model for Predicting the Radial Power Profile in a Fuel Pin. Water Reactor Fuel Element Performance Computer Modelling, 1983: p. 321335. 
52. Ainscough, J.B.H., H.J., Thermal Expansion of UO2, Thermal Reactor Data Sheet No 6. Central Electricity Generating Board, 1981.

53. Bond, G.G., A Review of Input Data for AGR Calculations using the Code SLEUTH-82. Central Electricity Generating Board, 1984. ND-R-1136(S).

54. Donaldson, A.T. and J.E. Harbottle, ZyBPC Data Sheet 1: In reactor Diametral Creep of PWR Fuel Cladding,. Nuclear Electric, 1991. ZyBPC/P(88)16(3).

55. Shea, J.H., The ENIGMA fuel performance code description: Version 5.14. EDF Energy, 2009. E/REP/BBFB/0039/GEN/07.

56. Assmann, H. and H. Stehle, Thermal and In-Reactor Densification of UO2 : Mechanisms and Experimental Results. Nuclear Engineering and Design, 1978. 48: p. 49-67.

57. Stehle, $\mathrm{H}$. and $\mathrm{H}$. Assmann, The dependence of in-reactor UO2 densification on temperature and microstructure. Journal of Nuclear Materials, 1974. 52: p. 303-308.

58. Hales, J.D., et al., BISON Theory Manual. Fuel Modelling \& Simulation Department, Idaho National Laboratory, 2013.

59. White, R.J., An analysis of Halden fuel stack length changes and comparison with UK sintering data. Halden Programme Group Meeting, 1990. HPR-336/13.

60. Siefken, L.J., et al., MATPRO - A Library of Materials Properties for Light-Water-Reactor Accident Analysis. Idaho National Engineering and Environmental Laboratory, 2001.

61. Shea, J.H., The ENIGMA fuel performance code user guide - Version 5.14. British Energy, 2009. E/REP/BBFB/0038/GEN/07.

62. Spino, J.R., J., W. Goll, and C.T. Walker, Matrix swelling rate and cavity volume balance of $\mathrm{UO}_{2}$ fuels at high burn-up. Journal of Nuclear Materials, 2005. 346: p. 131-144.

63. Kempter, C.P. and R.O. Elliott, Thermal Expansion of $\langle U N\rangle,\left\langle U \mathrm{O}_{2}\right\rangle,\left\langle U \mathrm{U}_{2} \mathrm{ThO}_{2}\right\rangle,\left\langle\mathrm{ThO}_{2}\right\rangle$. The Journal of Chemical Physics, 1959. 30(6): p. 1524-1526.

64. Clough, D.J. and N. Beatham, Thermal Reactor $\mathrm{UO}_{2}$ Data Sheet No. 10. EDF Energy, 1982. NDR-622(W): p. 1-7.

65. Wood, D.S. and B. Watkins, Creep Assessment of the Reactor Performance of Coldworked Zircaloy-2 Pressure Tubes at 270C. Central Electricity Generating Board, 1970. TRG Report 2047(C).

66. Nichols, P., Creep-rate and time to rupture correlations for an enlarged 20/25/Nb pressure test database. Central Electricity Generating Board, 1988. AGR/FPWG/P(88)1317.

67. Palmer, I.D., Uranium Dioxide Properties Data Manual Data Sheet 5 : Elastic Modulus. EDF Energy, 2014. E/REP/BCBB/0082/GEN/14: p. 1-18.

68. Lassmann, K., URGAP, A Gap Conductance Model for Transient Conditions. Water Reactor Fuel Element Performance Computer Modelling, 1983: p. 97-114.

69. Lassmann, K. and F. Hohlefeld, The revised URGAP model to describe the gap conductance between fuel and cladding. Nuclear Engineering and Design, 1987. 103: p. 215-221.

70. Beyer, C.E., et al., GAPCON-THERMAL-2: A computer program for calculating the thermal behavior of an oxide fuel rod. Battelle Pacific Northwest Laboratories, 1975. BNWL-1898.

71. Hashimoto, K., et al., Determination of the thermal conductivity of xenon-helium mixtures at high temperatures by the shock-tube method. International Journal of Thermophysics, 1992. 13(2): p. 211-221.

72. Evans, A.G. and R.W. Davidge, The strength and fracture of stochiometric polycrystaline UO2. Journal of Nuclear Materials, 1969. 33: p. 249-260.

73. Morgan, S., 2015. Personal Communication.

74. Backman, K., L. Hallstadius, and G. Ronnberg, Westinghouse Advanced Doped Pellet Characteristics and Irradiation Behaviour Advanced fuel pellet materials and fuel rod design for water cooled reactors, proceedings of a technical committee meeting held in Villigen, 2326 November 2009 (IAEA-TECDOC-1654), 2009: p. 117-126.

75. Nonon, C., et al., PCl behaviour of chromium oxide-doped fuel Pellet-Clad Interaction in Water Reactor Fuels Transactions, Aix-en-Provence, 2004: p. 305-319. 
76. Arborelius, J., et al., Advanced Doped $\mathrm{UO}_{2}$ Pellets in LWR Applications. Journal of Nuclear Science and Technology, 2006. 43(9): p. 967-976. 


\section{References}

1. Nonbol, E., Description of the Advanced Gas Cooled Type of Reactor (AGR). Riso National Laboratory, Roskilde, Denmark, 1996. NKS/RAK-2(96)TR-C2.

2. Cox, B., Pellet-clad interaction (PCI) failures of zirconium alloy fuel cladding - a review. Journal of Nuclear Materials, 1990. 172: p. 249-292.

3. Yagnik, S.K., D.J. Sunderland, and B.C. Cheng, Effect of PWR re-start ramp rate on pelletcladding interaction. Pellet-Clad Interaction in Water Reactor Fuels Transactions, Aix-enProvence, 2004: p. 63-77.

4. Michel, B., J. Sercombe, and G. Thouvenin, A new phenomenological criterion for pelletcladding interaction rupture. Nuclear Engineering and Design, 2008. 238(7): p. 1612-1628.

5. Bernaudat, C., Mechanical behaviour modelling of fractured nuclear fuel pellets. Nuclear Engineering and Design, 1995. 156: p. 373-381.

6. Brochard, J., et al., Modelling of Pellet Cladding Interaction in PWR fuel. Transactions, SMIRT 16, Washington DC, 2010. 1314.

7. Wood, J.C., PCI-OGRAMS: application of CANDU fuelogram methodology to PCl data from light water reactors. IAEA Specialists Meeting on Power Ramping and Power Cycling of Water Reactor Fuels; Arles, France, 1979. 17: p. 1-8.

8. Van Uffelen, P., et al., Review of operational requirements with respect to PCMI in a VVER and the corresponding developments in the transuranus code. Pellet-Clad Interaction in Water Reactor Fuels Transactions, Aix-en-Provence, 2004: p. 53-62.

9. Smirnov, A.V., et al., Pellet-Cladding Interaction In VVER Fuel Rods. Pellet-Clad Interaction in Water Reactor Fuels Transactions, Aix-en-Provence, 2004: p. 231-240.

10. Bond, G.G. and A.G. Uglow, A comparison between reactor experiments and sleuth-seer code predictions of pellet-clad interactions on AGR fuel pins. Nuclear Engineering and Design, 1980. 56: p. 135-141.

11. Shea, J.H., et al., Modelling the effects of flexible operation on AGR fuel integrity. TopFuel '97 Transactions, 1997. 5: p. 176-183.

12. Gittus, J.H., Theoretical analysis of the strains produced in nuclear fuel cladding tubes by the expansion of cracked cylindrical fuel pellets. Nuclear Engineering And Design, 1972. 18: p. 6982.

13. Armijo, J.S. and Z. Abdullahi, Pellet cladding interaction fuel failures during anticipated perational occurrences in boiling water reactors. United States Nuclear Regulatory Commission Report, 2009: p. 1-22.

14. Michel, B., et al., 3D fuel cracking modelling in pellet cladding mechanical interaction. Engineering Fracture Mechanics, 2008. 75(11): p. 3581-3598.

15. Beguin, S., PCl-related constraints on EDF PWRs and associated challenges. Pellet-Clad Interaction in Water Reactor Fuels Transactions, Aix-en-Provence, 2005: p. 53-62.

16. Mella, R. and M.R. Wenman, Modelling fracture of nuclear fuel pellets during a power transient using peridynamics. Journal of Nuclear Materials, 2015. 467: p. 58-67.

17. Morgan, S., et al., Understanding advanced gas-cooled reactor (CAGR) fuel using metallography. TopFuel 2012 Transactions, 2012: p. 515-519.

18. Huang, H.S., B. and J. Hales, Discrete element method for simulation of early-life thermal fracturing behavior in ceramic nuclear fuel pellets. Nuclear Engineering and Design, 2014. 278: p. 515-528.

19. Williford, R.E.L., D.D. and C.L. Mohr, $A$ model for the effective thermal and mechanical properties of cracked $U_{2}$ pellets. Nuclear Technology, 1981. 56: p. 340-350.

20. Walton, L.A. and D.L. Husser, Fuel Pellet Fracture and Relocation. Water Reactor Fuel Element Performance Computer Modelling, 1983: p. 115-152.

21. Oguma, M., Cracking and relocation behaviour of nuclear fuel pellets during rise to power. Nuclear Engineering and Design, 1983. 76: p. 35-45. 
22. Sercombe, J., R. Masson, and T. Helfer, Stress concentration during pellet cladding interaction: Comparison of closed-form solutions with $2 D(r, \vartheta)$ finite element simulations. Nuclear Engineering and Design, 2013. 260: p. 175-187.

23. Kim, Y.M., et al., Assessment of cladding relaxation and PCMI models in INFRA. Pellet-Clad Interaction in Water Reactor Fuels Transactions, Aix-en-Provence, 2004: p. 425-437.

24. Wiesenack, W. and T. Tverberg, PCMI of high burn-up fuel as manifested by different types of instrumentation and measurements in the Halden reactor experimental programme. PelletClad Interaction in Water Reactor Fuels Transactions, Aix-en-Provence, 2004: p. 321-332.

25. Suzuki, M., H. Saitou, and T. Fuketa, RANNS code analysis on the local mechanical conditions of cladding of high burnup fuel rods under PCMI in RIA-simulated experiments in NSRR. Nuclear Science and Technology, 2006. 43(9): p. 1097-1104.

26. Rossi, M.L. and C.D. Taylor, First-principles insights into the nature of zirconium-iodine interactions and the initiation of iodine-induced stress-corrosion cracking. Journal of Nuclear Materials, 2015. 458: p. 1-10.

27. Boyd, W.A. and G. Mangham, A Westinghouse Local Fuel Duty PCI Risk Monitor and Analysis Tool. TopFuel 2015 Transactions, 2015. 1: p. 303-312.

28. Sunderland, D.J., Reflections on 25 years of LWR fuel modeling, challenges and contemporary issues. Nuclear Science and Technology Interaction Program (NSTIP), ORNL, 2011.

29. Williamson, R.L., Enhancing the ABAQUS thermomechanics code to simulate multipellet steady and transient LWR fuel rod behavior. Journal of Nuclear Materials, 2011. 415(1): p. 74-83.

30. Soba, A. and A. Denis, Simulation with DIONISIO 1.0 of thermal and mechanical pelletcladding interaction in nuclear fuel rods. Journal of Nuclear Materials, 2008. 374: p. 32-43.

31. Mella, R. and M.R. Wenman, Axisymmetric whole pin life modelling of advanced gas-cooled reactor nuclear fuel. Journal of Nuclear Materials, 2013. 437(1-3): p. 154-165.

32. Liu, R.P., A., W. Zhou, and P.K. Chan, Multiphysics coupled modeling of light water reactor fuel performance. Progress in Nuclear Energy, 2016. 91: p. 38-48.

33. Walker, S.P., A. Yu, and R.T. Fenner, Pellet-clad mechanical interaction: Pellet-clad bond and strain relief. Nuclear Engineering and Design, 1992. 138: p. 403-408.

34. Yu, A., S.P. Walker, and R.T. Fenner, Pellet-clad bonding during PCMI. Nuclear Engineering and Design, 1990. 121: p. 53-58.

35. Marchal, N., C. Campos, and C. Garnier, Finite element simulation of Pellet-Cladding Interaction $(P C l)$ in nuclear fuel rods. Computational Materials Science, 2009. 45: p. 821-826.

36. Tonks, M.R., Modelling Reactor Fuel Material Behavior Based on Microstructure Rather Than Burn-Up. NUMAT - The Nuclear Materials Conference, Montpellier (France), 7-10th November 2016, 2016. Plenary Presentation.

37. Hales, J. and B.W.W. Spencer, R.L., Multidimensional modelling options in the BISON fuel performance code. NUMAT - The Nuclear Materials Conference, Montpellier (France), 7-10th November 2016, 2016. Poster Presentation: p. P2.88.

38. Sercombe, J., I. Aubrun, and C. Nonon, Power ramped cladding stresses and strains in 3D simulations with burnup-dependent pellet-clad friction. Nuclear Engineering and Design, 2012. 242: p. 164-181.

39. Williamson, R.L., et al., Multidimensional multiphysics simulation of nuclear fuel behavior. Journal of Nuclear Materials, 2012. 423(1-3): p. 149-163.

40. Baurens, B., et al., 3D thermo-chemical-mechanical simulation of power ramps with ALCYONE fuel code. Journal of Nuclear Materials, 2014. 452: p. 578-594.

41. Lassmann, K.B., H., Modelling the fuel rod behaviour and recent advances of the TRANSURANUS code. Nuclear Engineering and Design, 1988. 106: p. 291-313.

42. Jernkvist, L.O., A continuum model for cracked $\mathrm{UO}_{2}$ fuel. Nuclear Engineering and Design, 1997. 176: p. 273-284. 
43. Shea, J.H., A Review of the ENIGMA Fuel Pellet Mechanical Model. British Energy, 2002. E/REP/REAC/0060/GEN/02: p. 1-12.

44. Williford, R.E. and D.D. Lanning, Cracked Fuel Mechanics. Water Reactor Fuel Element Performance Computer Modelling, 1983. 1: p. 153-186.

45. Williford, R.E., D.D. Lanning, and C.L. Mohr, A model for the effective thermal and mechanical properties of cracked $\cup_{2}$ pellets. Nuclear Technology, 1981. 56: p. 340-350.

46. Guicheret-Retel, V., et al., Elastic and viscoplastic pellets fragmentation modeling using an axisymmetrical 1D finite element code. Nuclear engineering and Technology, 2004. 232: p. 249-262.

47. Guicheret-Retel, V., et al., Modelling 3-D Mechanical Phenomena in a 1-D Industria; Finite Element Code : Results and Perspectives. Pellet-Clad Interaction in Water Reactor Fuels Transactions, Aix-en-Provence, 2004: p. 453-463.

48. Haynes, T.A., et al., Modelling pellet-clad mechanical interaction during operational transients in bonded nuclear fuel. Journal of Nuclear Materials, 2015. 465: p. 280-292.

49. Haynes, T.A., et al., Finite element modelling of pellet-clad interaction during operational transients. TopFuel 2015 Oral Transactions, 2015: p. 62-71.

50. Sheppard, D.O., Data Report IFA-507 From B.O.L. to 15.4 MWd/kgUO2. OECD Halden Reactor Project, 1982. HWR-74.

51. Palmer, I.D., K.W. Hesketh, and P.A. Jackson, A Model for Predicting the Radial Power Profile in a Fuel Pin. Water Reactor Fuel Element Performance Computer Modelling, 1983: p. 321335.

52. Ainscough, J.B.H., H.J., Thermal Expansion of UO2, Thermal Reactor Data Sheet No 6. Central Electricity Generating Board, 1981.

53. Bond, G.G., A Review of Input Data for AGR Calculations using the Code SLEUTH-82. Central Electricity Generating Board, 1984. ND-R-1136(S).

54. Donaldson, A.T. and J.E. Harbottle, ZyBPC Data Sheet 1: In reactor Diametral Creep of PWR Fuel Cladding,. Nuclear Electric, 1991. ZyBPC/P(88)16(3).

55. Shea, J.H., The ENIGMA fuel performance code description: Version 5.14. EDF Energy, 2009. E/REP/BBFB/0039/GEN/07.

56. Assmann, H. and H. Stehle, Thermal and In-Reactor Densification of UO2 : Mechanisms and Experimental Results. Nuclear Engineering and Design, 1978. 48: p. 49-67.

57. Stehle, H. and H. Assmann, The dependence of in-reactor UO2 densification on temperature and microstructure. Journal of Nuclear Materials, 1974. 52: p. 303-308.

58. Hales, J.D., et al., BISON Theory Manual. Fuel Modelling \& Simulation Department, Idaho National Laboratory, 2013.

59. White, R.J., An analysis of Halden fuel stack length changes and comparison with UK sintering data. Halden Programme Group Meeting, 1990. HPR-336/13.

60. Siefken, L.J., et al., MATPRO - A Library of Materials Properties for Light-Water-Reactor Accident Analysis. Idaho National Engineering and Environmental Laboratory, 2001.

61. Shea, J.H., The ENIGMA fuel performance code user guide - Version 5.14. British Energy, 2009. E/REP/BBFB/0038/GEN/07.

62. Spino, J.R., J., W. Goll, and C.T. Walker, Matrix swelling rate and cavity volume balance of $\mathrm{UO}_{2}$ fuels at high burn-up. Journal of Nuclear Materials, 2005. 346: p. 131-144.

63. Kempter, C.P. and R.O. Elliott, Thermal Expansion of $\langle U N\rangle,\left\langle U \mathrm{O}_{2}\right\rangle,\left\langle U \mathrm{UO}_{2} \mathrm{ThO}_{2}\right\rangle,\left\langle\mathrm{ThO}_{2}\right\rangle$. The Journal of Chemical Physics, 1959. 30(6): p. 1524-1526.

64. Clough, D.J. and N. Beatham, Thermal Reactor UO ${ }_{2}$ Data Sheet No. 10. EDF Energy, 1982. NDR-622(W): p. $1-7$.

65. Wood, D.S. and B. Watkins, Creep Assessment of the Reactor Performance of Coldworked Zircaloy-2 Pressure Tubes at 270C. Central Electricity Generating Board, 1970. TRG Report 2047(C). 
66. Nichols, P., Creep-rate and time to rupture correlations for an enlarged 20/25/Nb pressure test database. Central Electricity Generating Board, 1988. AGR/FPWG/P(88)1317.

67. Palmer, I.D., Uranium Dioxide Properties Data Manual Data Sheet 5 : Elastic Modulus. EDF Energy, 2014. E/REP/BCBB/0082/GEN/14: p. 1-18.

68. Lassmann, K., URGAP, A Gap Conductance Model for Transient Conditions. Water Reactor Fuel Element Performance Computer Modelling, 1983: p. 97-114.

69. Lassmann, K. and F. Hohlefeld, The revised URGAP model to describe the gap conductance between fuel and cladding. Nuclear Engineering and Design, 1987. 103: p. 215-221.

70. Beyer, C.E., et al., GAPCON-THERMAL-2: A computer program for calculating the thermal behavior of an oxide fuel rod. Battelle Pacific Northwest Laboratories, 1975. BNWL-1898.

71. Hashimoto, K., et al., Determination of the thermal conductivity of xenon-helium mixtures at high temperatures by the shock-tube method. International Journal of Thermophysics, 1992. 13(2): p. 211-221.

72. Evans, A.G. and R.W. Davidge, The strength and fracture of stochiometric polycrystaline UO2. Journal of Nuclear Materials, 1969. 33: p. 249-260.

73. Morgan, S., 2015. Personal Communication.

74. Backman, K., L. Hallstadius, and G. Ronnberg, Westinghouse Advanced Doped Pellet Characteristics and Irradiation Behaviour Advanced fuel pellet materials and fuel rod design for water cooled reactors, proceedings of a technical committee meeting held in Villigen, 2326 November 2009 (IAEA-TECDOC-1654), 2009: p. 117-126.

75. Nonon, C., et al., PCl behaviour of chromium oxide-doped fuel Pellet-Clad Interaction in Water Reactor Fuels Transactions, Aix-en-Provence, 2004: p. 305-319.

76. Arborelius, J., et al., Advanced Doped $\cup_{2}$ Pellets in LWR Applications. Journal of Nuclear Science and Technology, 2006. 43(9): p. 967-976. 


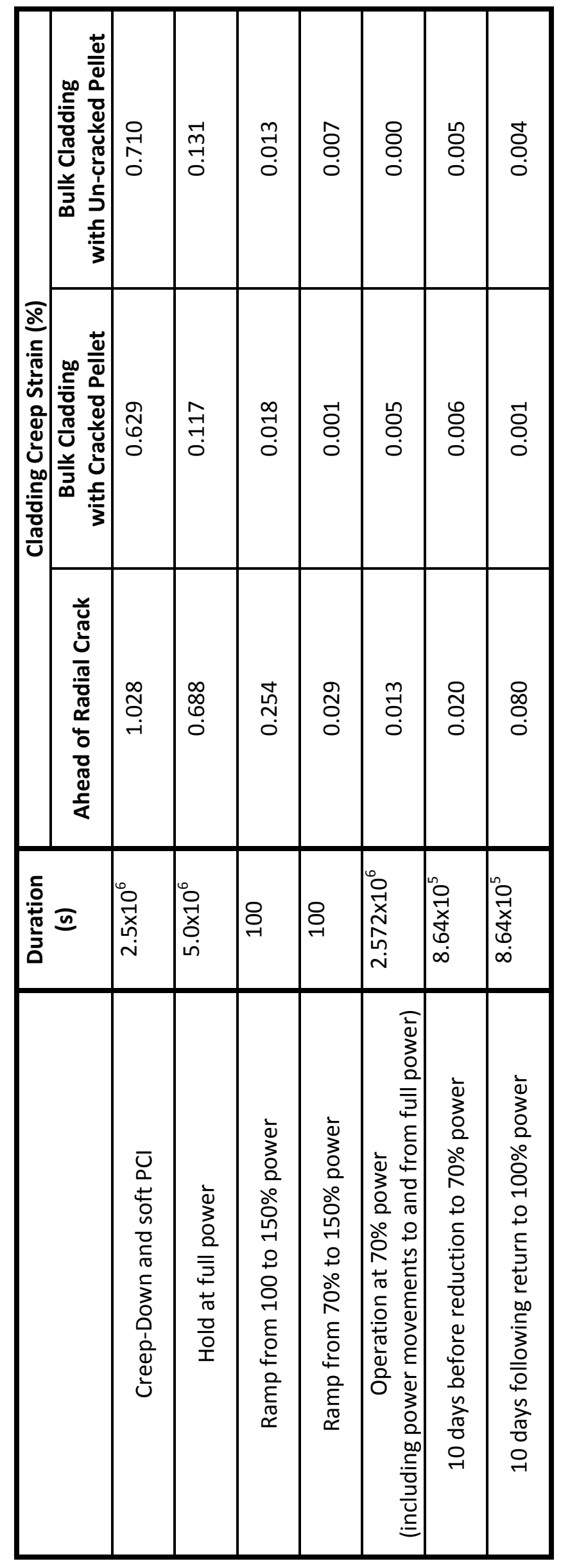




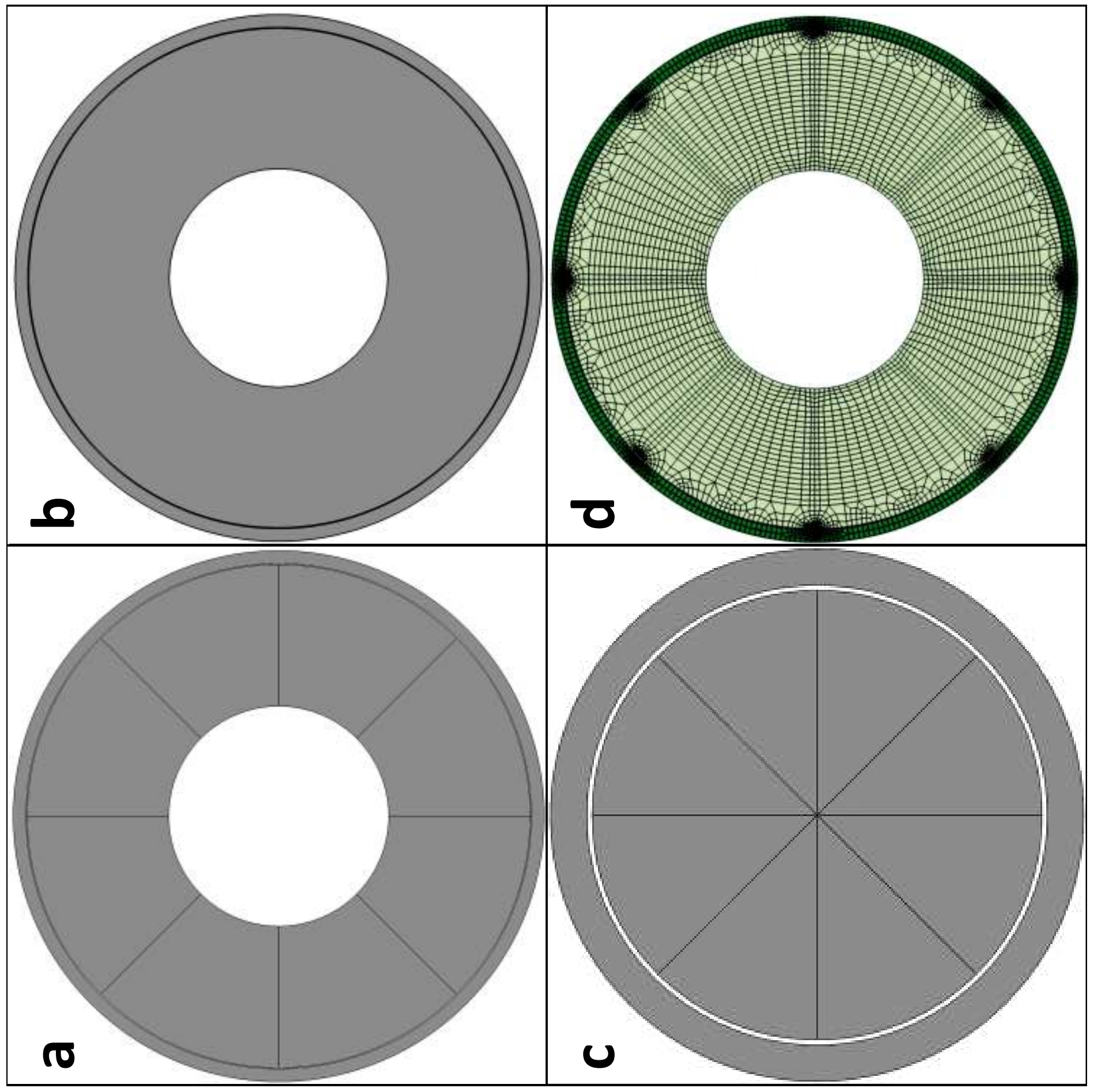

高 


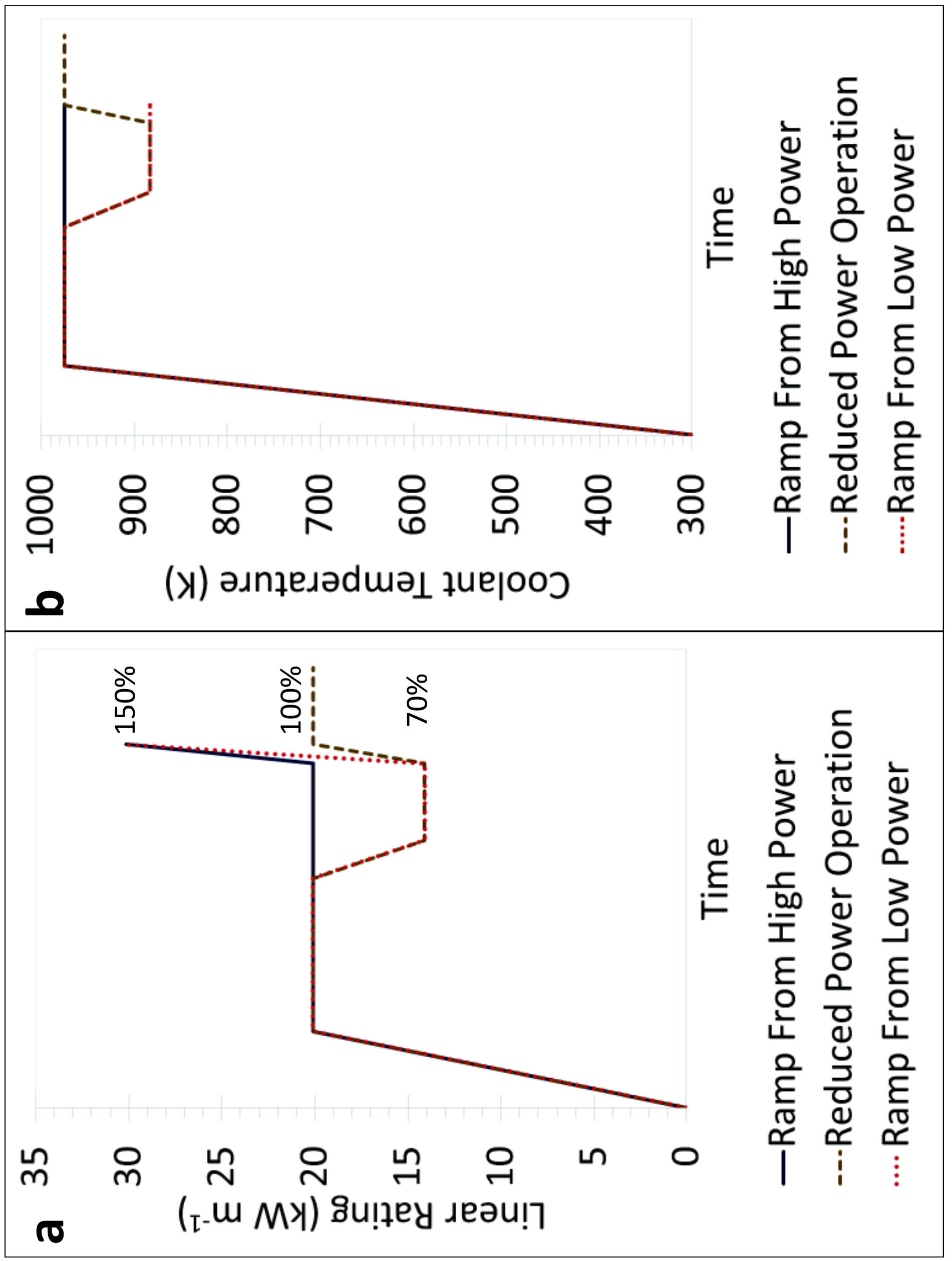




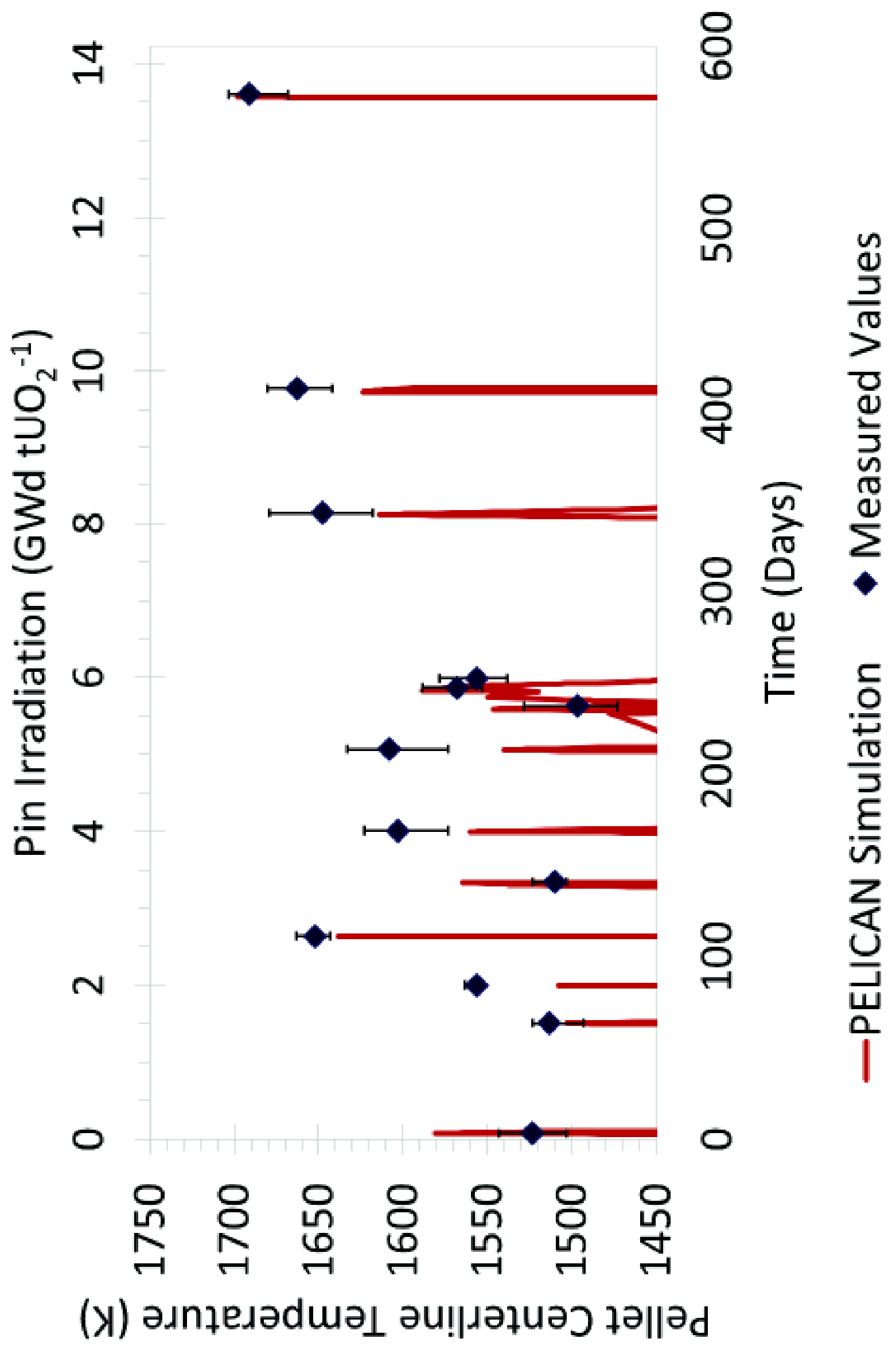




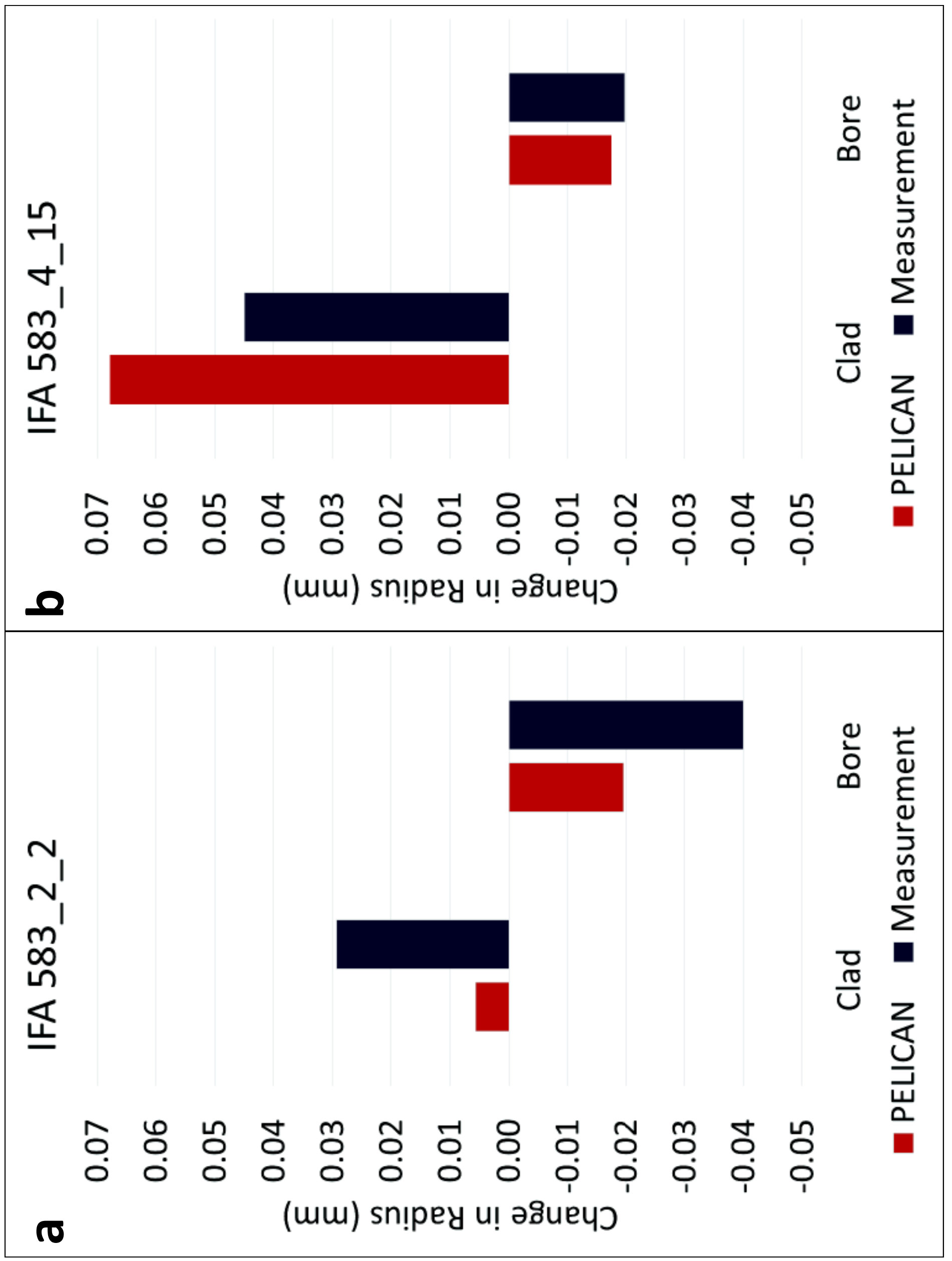




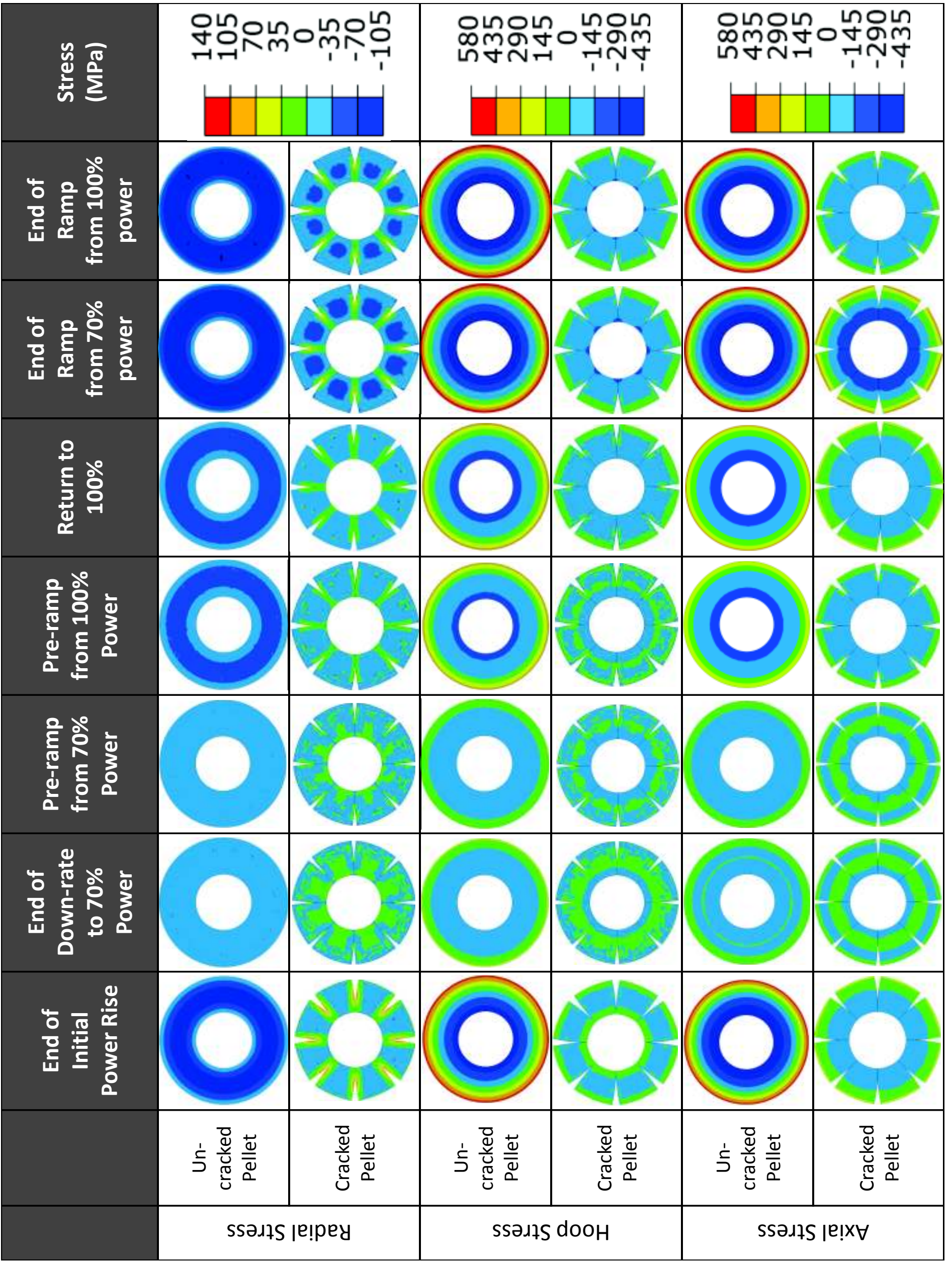




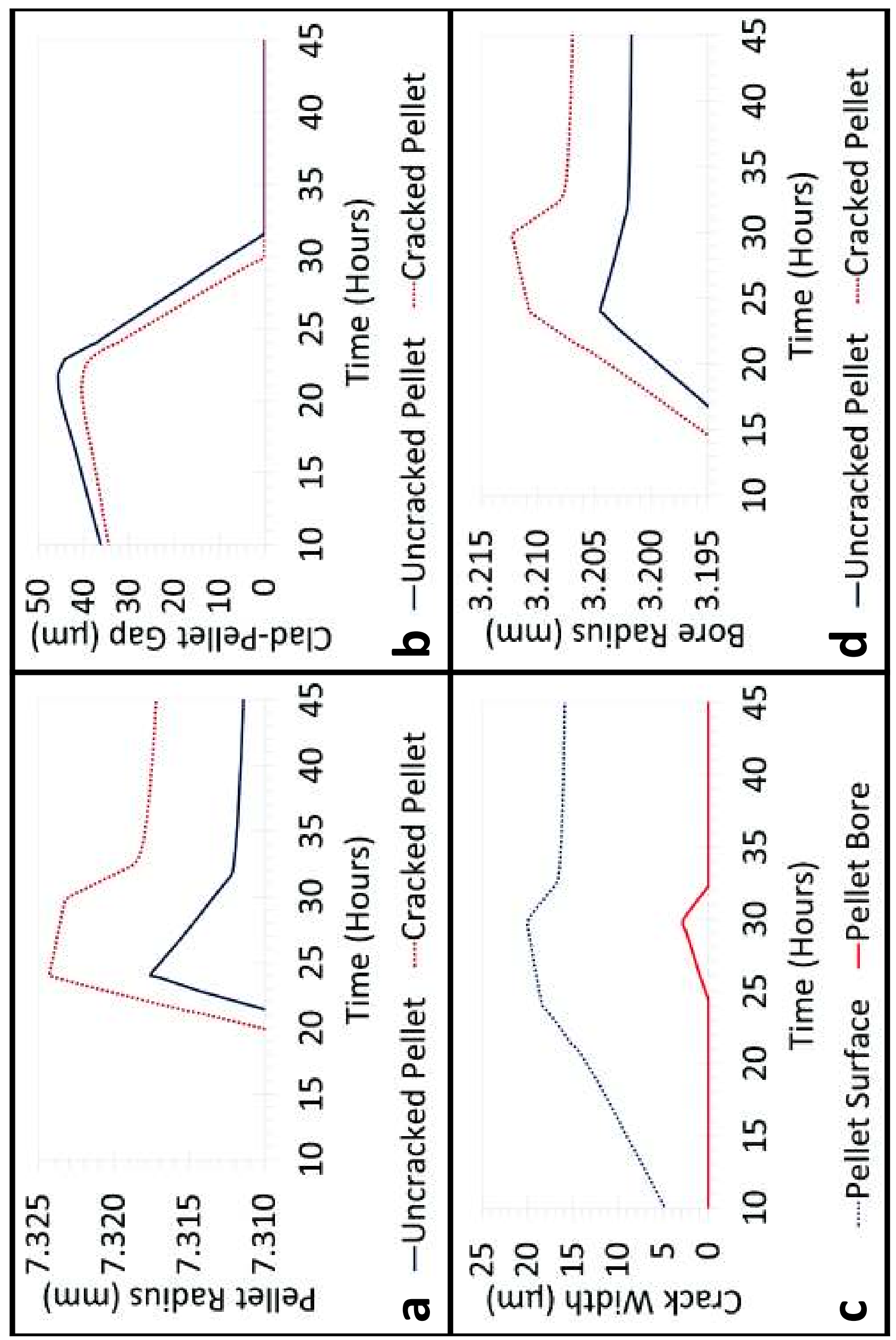




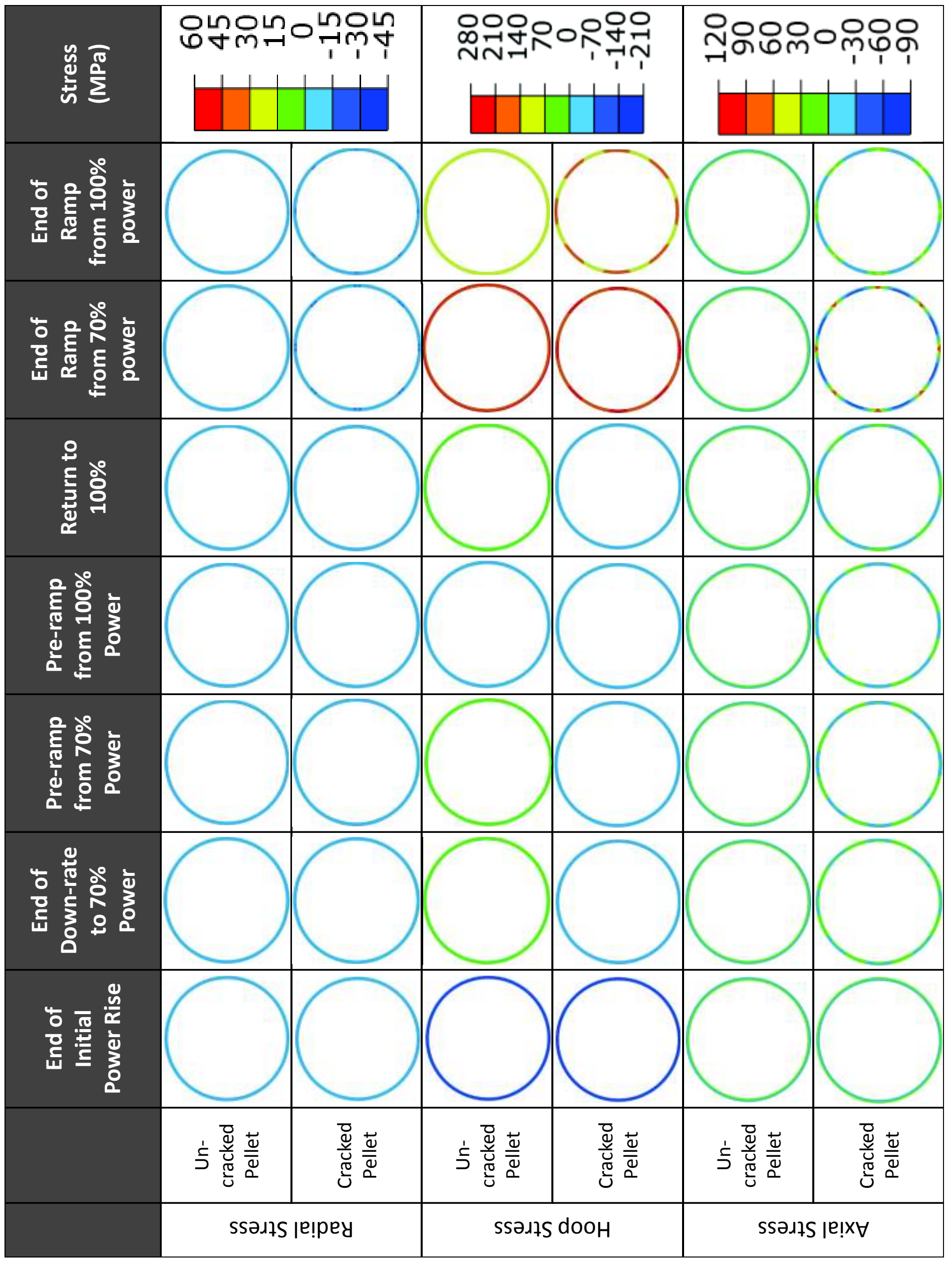




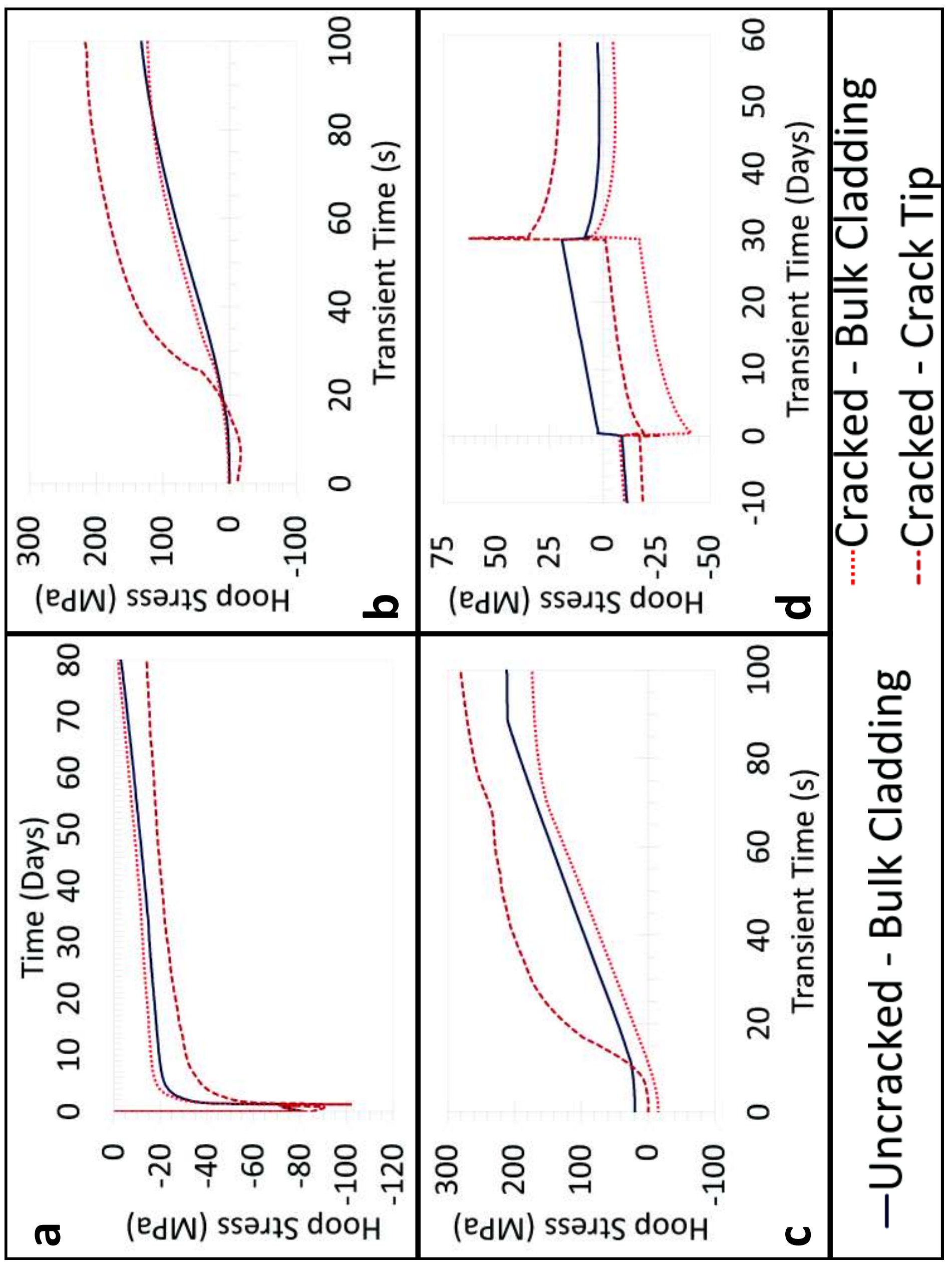




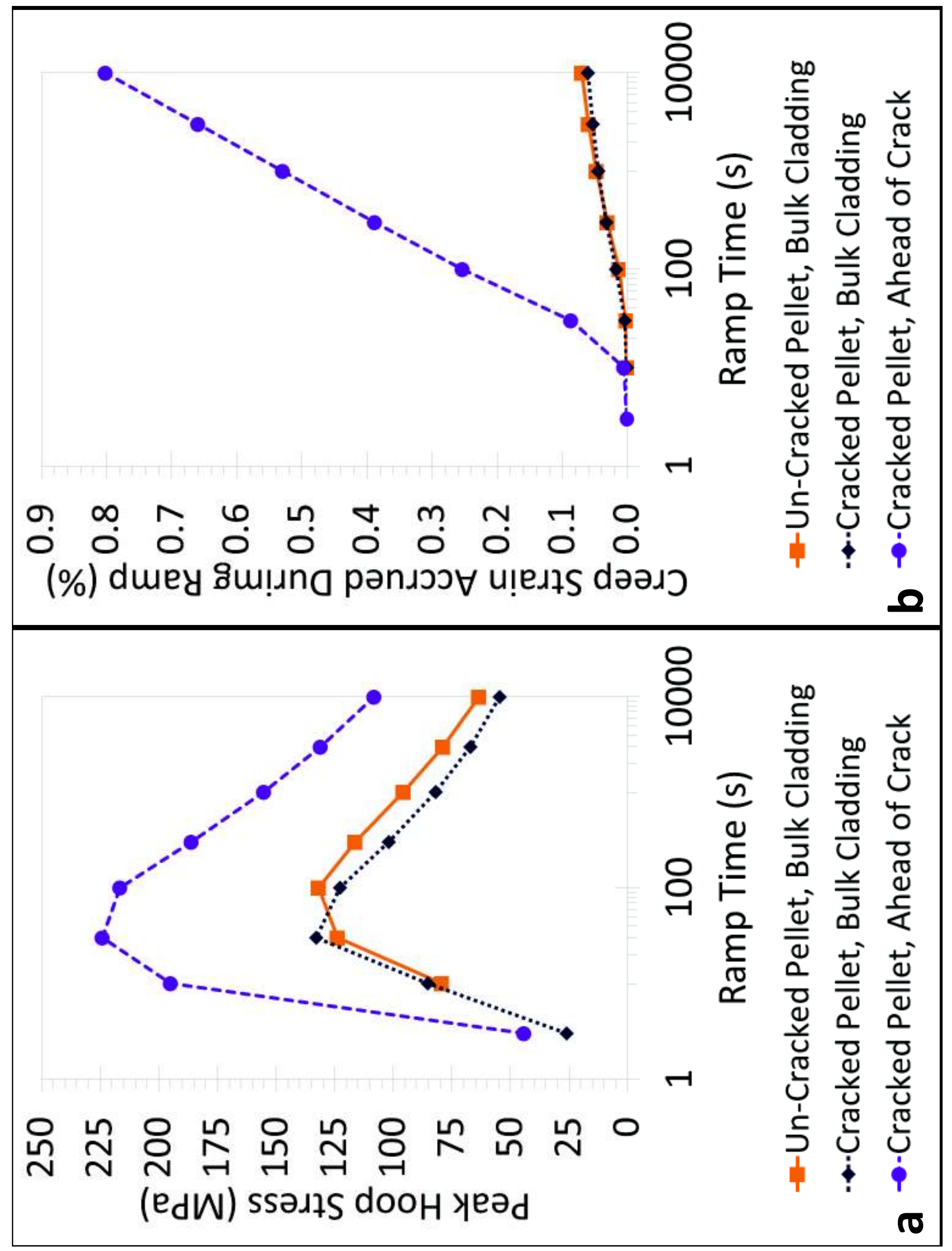




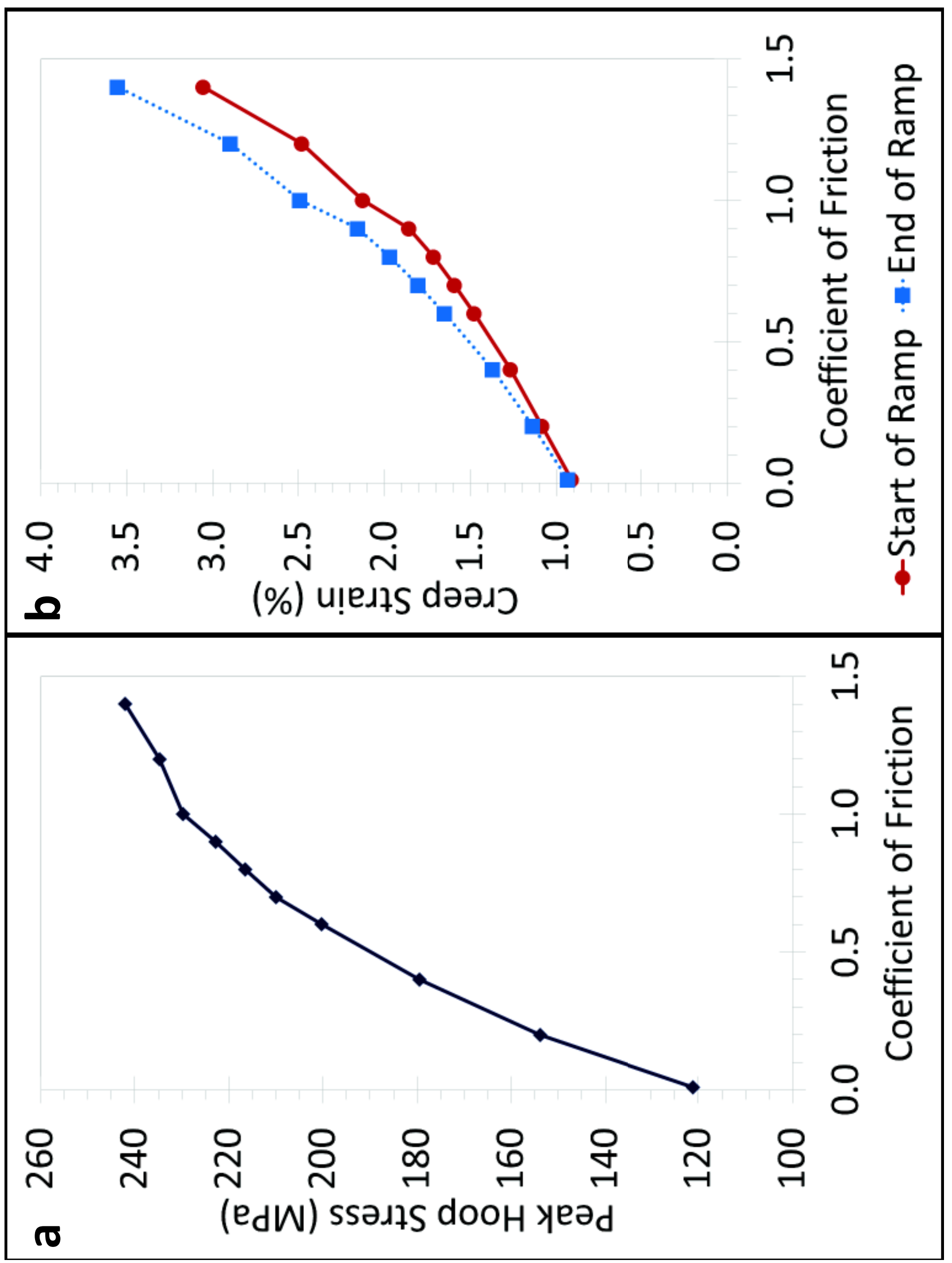




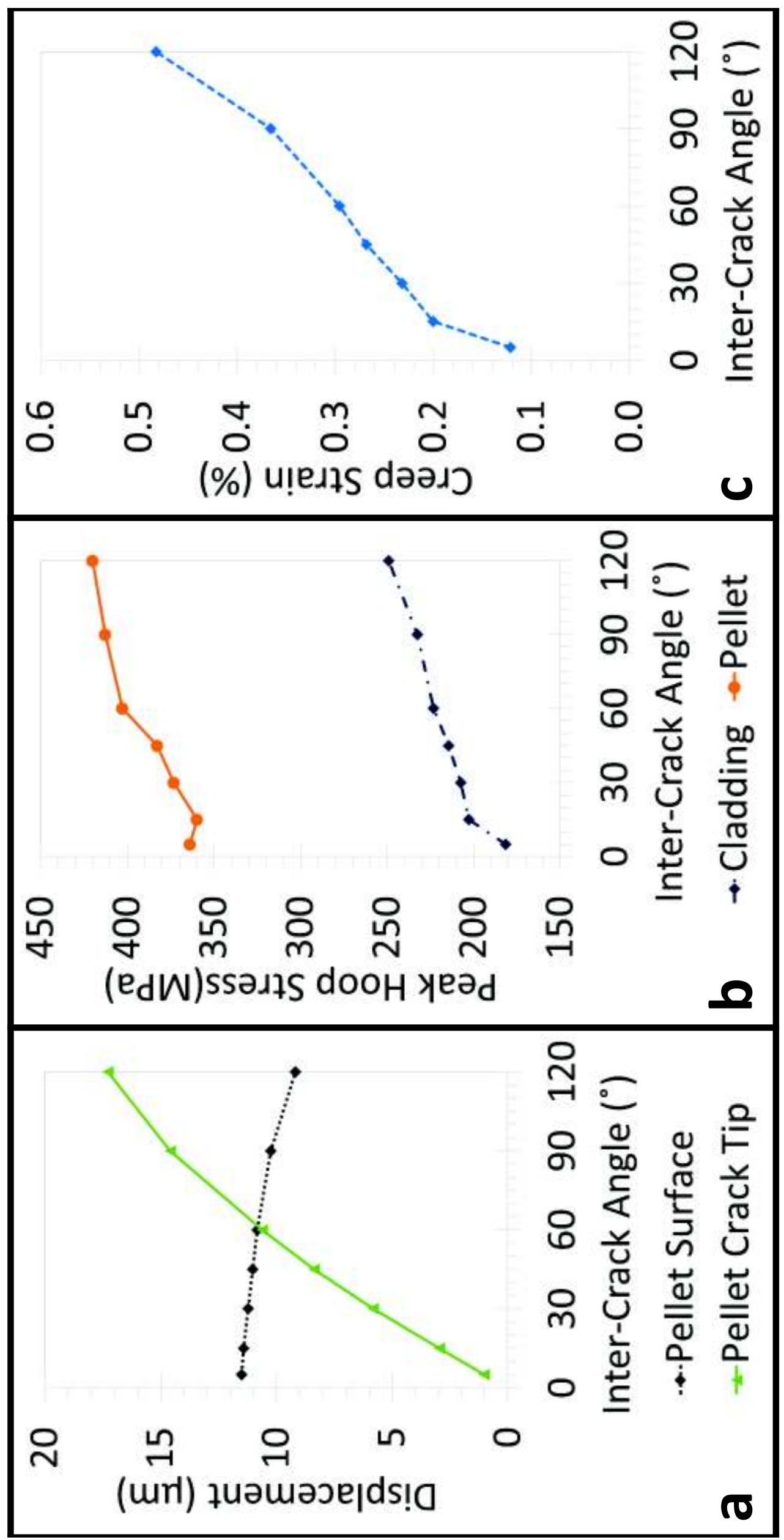

